\title{
An illustrated key to the morphospecies of terrestrial isopods (Crustacea: Oniscidea) of Barrow Island, Western Australia
}

\author{
Simon Judd ${ }^{1}$ and Giulia Perina ${ }^{2}$ \\ ${ }^{1}$ Phoenix Environmental Sciences, 1/511 Wanneroo Road, Balcatta, Western Australia 6021, Australia. \\ Email: simon.judd@phoenixenv.com.au. Author for correspondence. \\ 2 Subterranean Ecology Pty Ltd, Suite 8, 37 Cedric Street, Stirling, Western Australia 6021, Australia. \\ Email: giulia.perina@alice.it
}

\begin{abstract}
This paper presents an illustrated key to eighteen morphospecies of terrestrial isopods from Barrow Island with a brief summary regarding their currently known distribution and potential endemicity to the island. Six described species are recorded, Ligia exotica (family Ligiidae), Alloniscus pallidulus (Alloniscidae), Laevophiloscia yalgooensis (Philosciidae), Porcellionides pruinosus (Porcellionidae), Barrowdillo pseudopyrgoniscus, Buddelundia hirsuta (both Armadillidae), but the identifications of most need to be confirmed following genus-level revisions and examination of typeor topotypical material. The key includes twelve undescribed species and at least two undescribed genera from the family Armadillidae, one of which is apparently restricted to Barrow Island. Although there is still considerable taxonomic work required to evaluate distributions, it appears that at least six of the eighteen species are potential short-range endemics (SRE).
\end{abstract}

KEYWORDS: Armadillidae, Buddelundia, Barrowdillo, Pilbara, Isopoda, taxonomy

\section{INTRODUCTION}

In Western Australia (WA) terrestrial isopods (Crustacea: Oniscidea) have received little attention in the scientific literature. The first species descriptions from WA were compiled by Budde-Lund in 1912, but his work remained unfinished and not comprehensively illustrated. In recent years, taxonomic works have been limited to the description of new species from Cape Range (Dalens 1992), the Kimberley and Barrow Island (Dalens 1993) and calcretes in the Murchison Region (Taiti and Humphreys 2001). Very few species can be identified based on the original taxonomic literature because most of the descriptions are incomplete by modern taxonomic standards and poorly illustrated. Moreover, the taxonomy of the Armadillidae, the dominant group in the driest parts of the Western Australia, has been confused by different interpretations and nomenclatural problems (Taiti et al. 1998). Placing new species within the correct genera is therefore highly problematic without undertaking a complete revision of the Australian Armadillidae.
Discovery of large gas deposits prompted Chevron Australia Pty Ltd to make an application to construct an industrial plant to liquefy natural gas on the island in 2001. Part of the process involved an environmental impact assessment which included a baseline survey of the terrestrial invertebrate fauna (Callan et al. 2011). Sampling occurred from 2005-2007 and rationale for site selection and detailed methodology was given in Callan et al. (2011). Prior to this survey, only four species of terrestrial isopods had been recorded from Barrow Island (Dalens 1993). These were: Ligia exotica Roux, 1828, Olibrinus sp., Laevophiloscia yalgoonensis Wahrberg, 1922 and Barrowdillo pseudopyrgoniscus Dalens, 1993. This paper illustrates the terrestrial isopods collected by this survey and subsequent quarantine surveillance for non-indigenous species (see Callan et al. 2011). Eighteen morphospecies are detailed which are likely to belong to eleven genera of the families Ligiidae, Olibrinidae, Alloniscidae, Philosciidae, Porcellionidae and Armadillidae.

The purpose of this paper is to document and to 
provide a tool to enable the determination of these morphospecies. The formal description of the new species and the confirmation of some nominal species reported require a more comprehensive taxonomic work and is beyond the scope of this paper.

\section{MATERIALS AND METHODS}

The majority of the material studied in this paper was collected as part of the baseline study outlined above. Original determinations were made by the first author in 2008 and the data derived from this work is included in Callan et al. (2011). For this paper, the best material from the baseline study was reexamined. Further material collected between March 2010 and March 2012 as part of quarantine surveillance was also included. All specimens are lodged at the Western Australian Museum (WAM) and registration numbers are provided.

The images of the specimens used in the key were photographed using a Leica DFC420 digital camera mounted on a Leica M205C stereo microscope and stacked montages were created using the Leica Application Suite V3 automontage software. The key is followed by a list of the morphospecies including the material examined, other available data, the taxonomic status and the main characters used to identify each taxon. Sites codes in the list of material examined are the same as those used by Callan et al. (2011). Distribution maps, derived from the coordinates in the list of material examined, are included along with an indication if the taxon is found elsewhere or whether it is likely to be a short-range endemic (SRE) species (Harvey 2002).

\section{KEY TOTHE TERRESTRIAL ISOPODS OF BARROW ISLAND}

1. Flagellum of second antenna consisting of more than 5 segments (Figures 1, 2) ............... 2

Flagellum of second antenna 2- or 3-segmented (Figures 6, 7)................................ 3

2. Eye large, consisting of more than 100 ommatidia. Ligia exotica (Figure 1)

Eye small, consisting of 5 ommatidia . Olibrinus sp. (Figure 2, 3)
3. Uropod exopodites long, extending beyond uropod protopodite (Figure 4) . .4

Uropod exopodites short, not extending beyond uropod protopodite (Figure 5)............ 6

4. Flagellum of second antenna 3-segmented (Figure 6) 5

Flagellum of second antenna 2-segmented (Figure 7) Porcellionides pruinosus (Figure 8)

5. Epimera of pleonites 3-5 long and tapered; outline of pereon and pleon a smooth line; noduli laterales absent

Alloniscus pallidulus (Figure 9)

Epimera of pleonites 3-5 reduced; pleon narrower than pereon, outline of pereon and pleon a stepped line; noduli laterales present (Figure 10)

Laevophiloscia yalgoonensis (Figure 11)

6. Pleopod exopodites interlocking with fourth pair large and overlapping the fifth pair (Figure 12) which is not visible in ventral view..... . .7

Pleopod exopodites not interlocking with the fifth pair visible (Figure 13) 15

7. Ventral surface of pereonite 1 and pereonite 2 without interlocking structures, but with small rounded bumps (Figure 14); uropod exopodites extending almost to the distal margin of the protopodite (Figure 15) .Armadillidae genus $1 \mathrm{sp} .1$ (Figure 16)

Interlocking structures present on pereonites, either in the form of divergent inner and outer lobes forming a cleft (schisma) on posterior corner of pereonite 1 (Figure 17) or a large tooth-like inner lobe present on ventral surface of epimera of pereonite 1 and 2 (Figure 18); uropod exopodites not extending to the distal margin of the protopodite (Figure 5) .8 
8. Dorsal surface convex but with epimera horizontal, or tending horizontal, at the distal margin (Figure 19); schisma absent on pereonite 1; dorsal surface tuberculate or with shallow bumps; uropod protopodite longer than broad and tapering (Figure 20)

... 9

Dorsal surface convex with vertical epimera; schisma present on pereonite 1 (Figure 17); dorsal surface without tubercles; uropod protopodite not longer than broad and not tapering (Figure 21) 10

9. Dorsal surface with well-developed tubercules; epimera horizontal (Figure 19) ...... Barrowdillo pseudopyrgoniscus (Figure 22)

Dorsal surface with sparse shallow bumps; epimera not horizontal but tending horizontal at the margins.

Armadillidae genus 2 sp.1 (Figure 23)

10. Frontal shield not divided into upper and lower sections by a transverse groove (Figure 24) 11

Frontal shield divided into upper and lower sections by a transverse groove (Figure 25)

11. Dorsal surface covered with short setae; well-defined interlocking lobe structures present on the ventral surface of epimera of pereonites 5-7 and pleonite 3 (Figure 26) Buddelundia sp. 1 (Figure 27)

Dorsal surface without setae; interlocking lobe structures absent on the ventral surface of epimera of pereonites 5-7 and pleonite 3 (Figure 28)

.Buddelundia sp. 2 (Figure 29)

12. Dorsal surface with long setae; interlocking lobes on ventral surface of epimera of pleonite 3 (Figure 30) ..... Buddelundia hirsuta (Figure 31)

Dorsal surface without setae; pleonite 3 without interlocking lobes
13. Sulcus arcuatus (longitudinal groove parallel to lateral margin of epimera of pereonite 1) prominent (Figure 17); male with protuberances above clypeus (Figure 25).......... Buddelundia sp. 3 (Figure 32)

Sulcus arcuatus absent (Figure 33) or indistinct shallow depression (Figure 34); male without protuberances above clypeus. 14

14. Inner lobe of schisma on pereonite 1 longer than outer lobe when viewed laterally (Figure 33); large tooth-like lobe on ventral surface of epimera of pereonite 2 (Figure 35)

Buddelundia sp. 4 (Figure 36)

Inner lobe of schisma on pereonite 1 shorter than outer lobe when viewed laterally (Figure 34); moderate tooth-like lobe on ventral surface epimera of pereonite 2 (Figure 37) ....... Buddelundia sp. 5 (Figure 38)

15. Frontal shield raised from vertex (Figure 39); uropod protopodite with distal part long and tapering (Figure 13) 16

Frontal shield flat to vertex (Figure 40); uropod protopodite with distal part short, quadrangular, approximately equally as wide as long (Figure 41) 17

16. Dorsal surface with tubercles .Armadillidae genus $3 \mathrm{sp.} 1$ (Figure 42)

Dorsal surface rough but with no distinct tubercles

Armadillidae genus 3 sp. 2 (Figure 43)

17. Lateral groove on pereonite 1 wide (Figure 40) and dorsal surface without setae. Armadillidae genus 4 sp. 1 (Figure 44)

Lateral groove on pereonite 1 narrow (Figure $45)$ and dorsal surface covered in short setae Armadillidae genus 4 sp. 2 (Figure 46) 


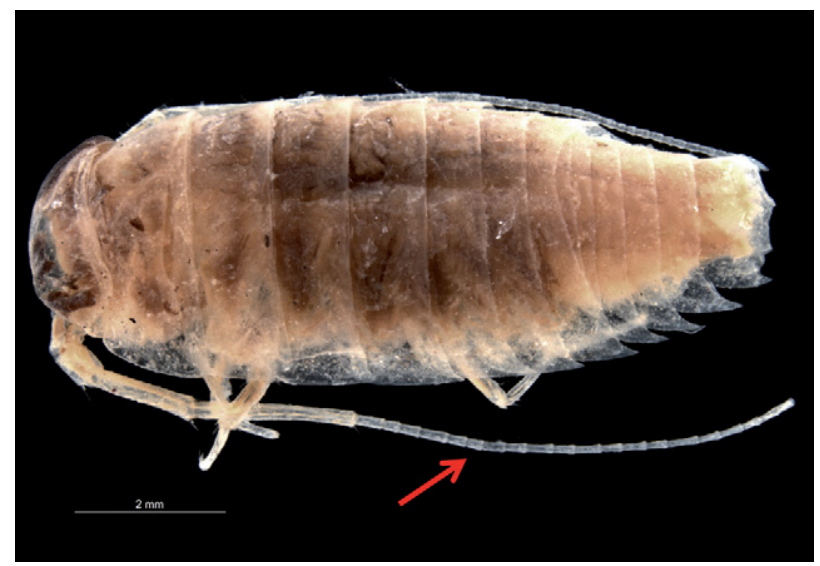

FIGURE 1

Ligia exotica, habitus, dorsal view. Arrow: flagellum of second antenna with more than 5 segments (WAM C1440)

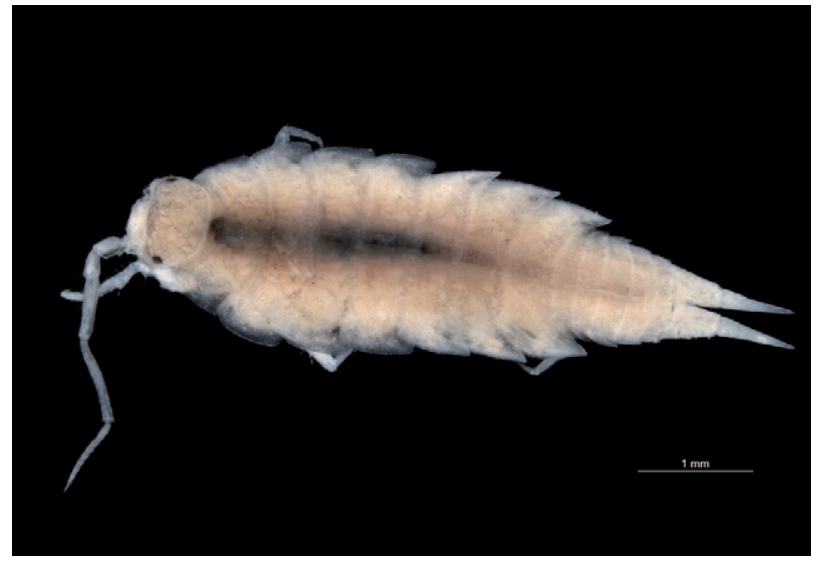

FIGURE 3

Olibrinus sp., habitus, dorsal view. (WAM 127-91).

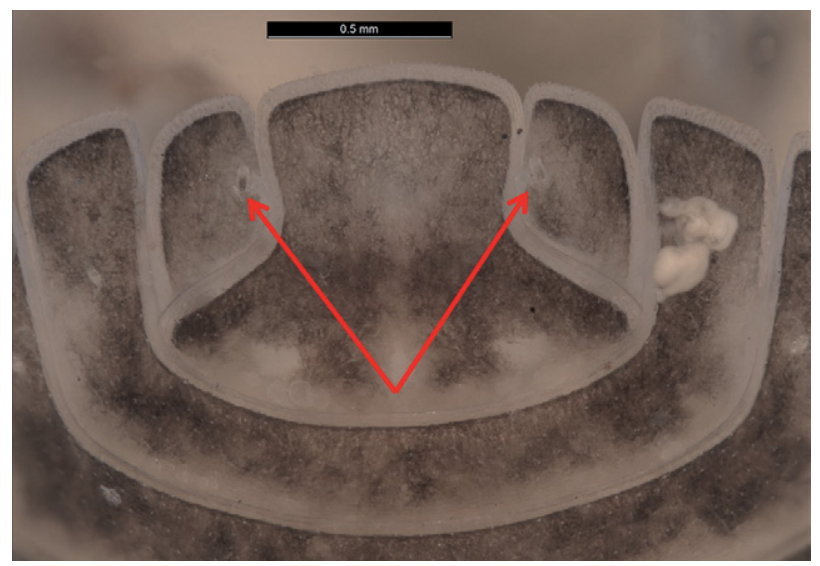

FIGURE 5

Buddelundia sp. 5, pleon, dorsal view. Arrows: uropod exopodites short (WAM C51810).

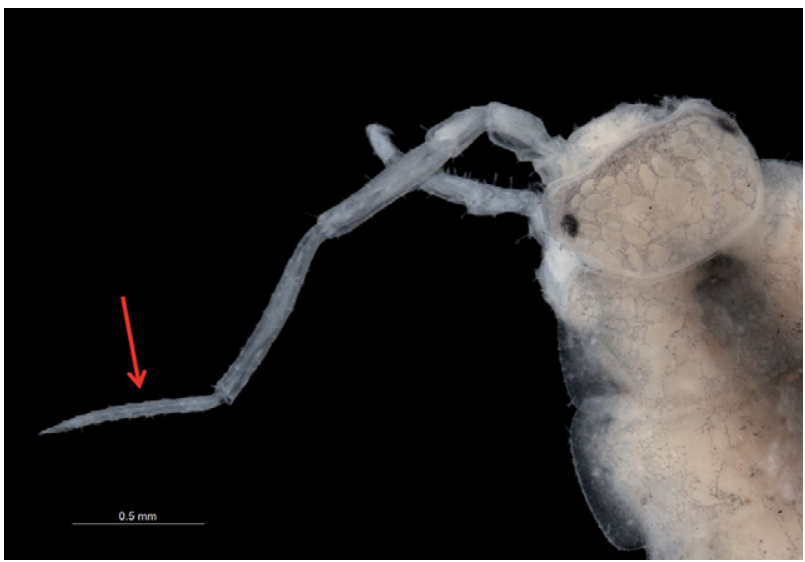

FIGURE 2 Olibrinus sp., head, dorsal view. Arrow: flagellum of second antenna with more than 5 segments (WAM 127-91).

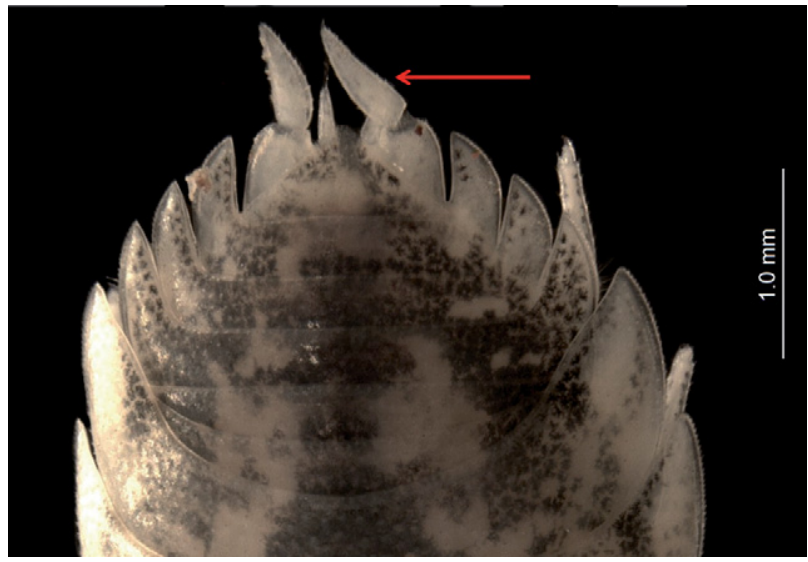

FIGURE 4

Alloniscus pallidulus, pleon, dorsal view. Arrow: uropod exopodite long (WAM C51828).

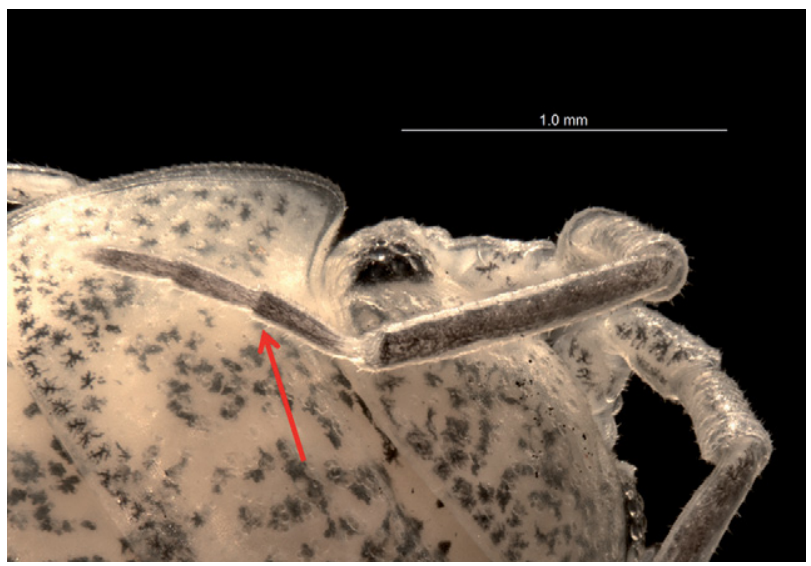

FIGURE 6 Alloniscus pallidulus, head, dorsal view. Arrow: flagellum of second antenna 3-segmented (WAM C51828). 


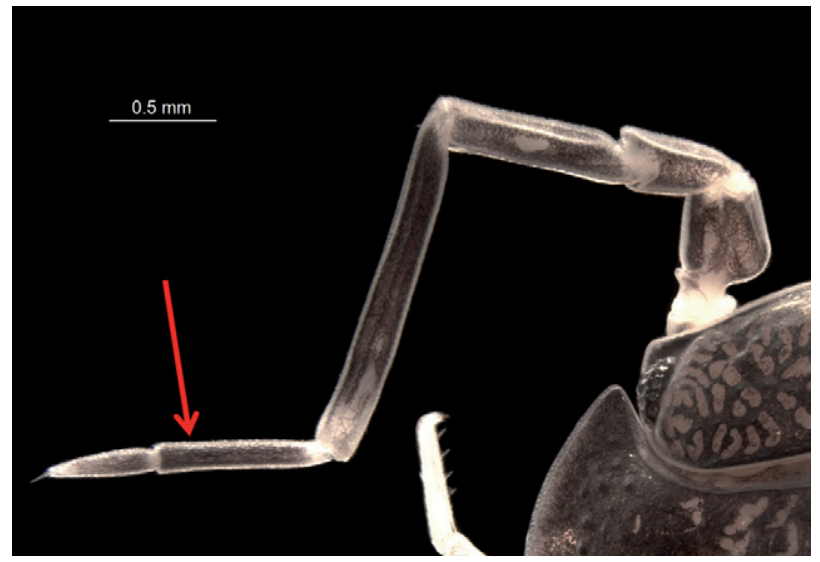

FIGURE 7
Porcellionides pruinosus, head, partial dorsal view. Arrow: flagellum of second antenna 2-segmented (WAM C51824),

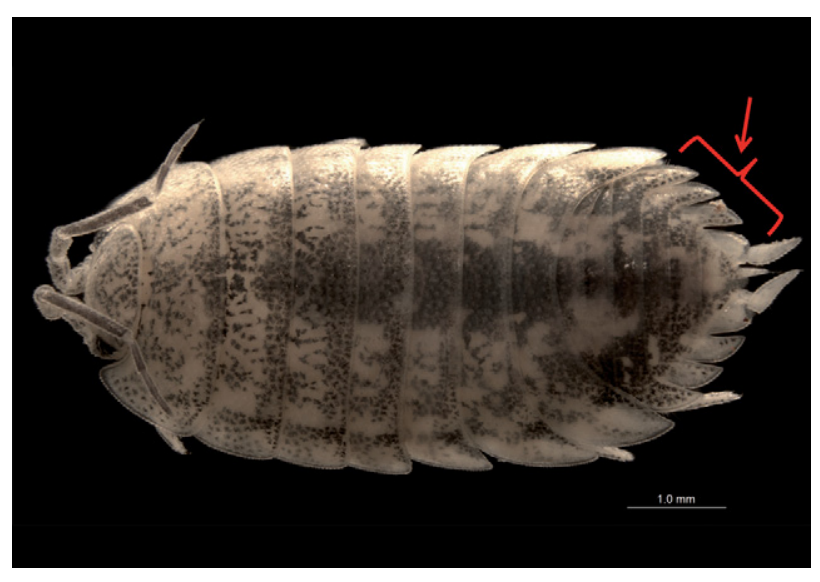

FIGURE 9

Alloniscus pallidulus, habitus, dorsal view. Arrow: epimera of pleonites 3-5 long and tapered (WAM C51828).

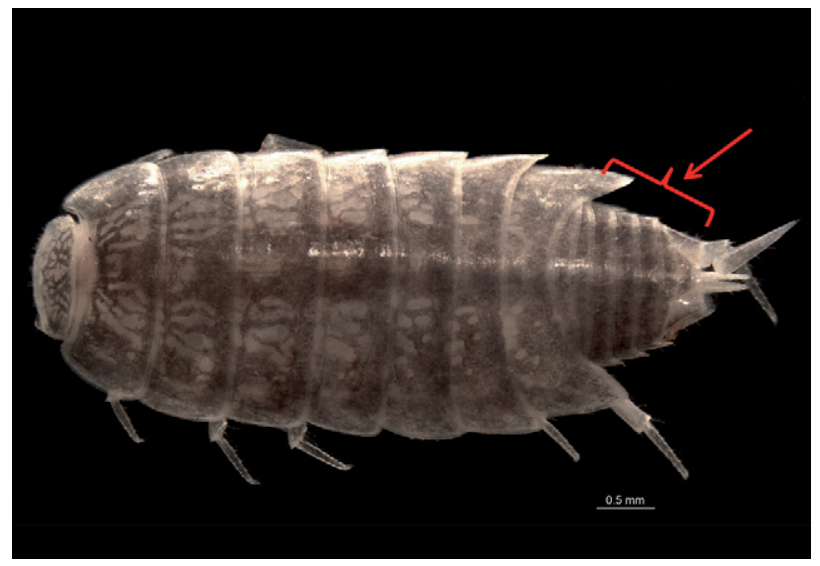

FIGURE 11

Laevophiloscia yalgoonensis, habitus, dorsal view. Arrow: epimera of pleonites 3-5 reduced, pleon narrower than pereon (WAM C51821)

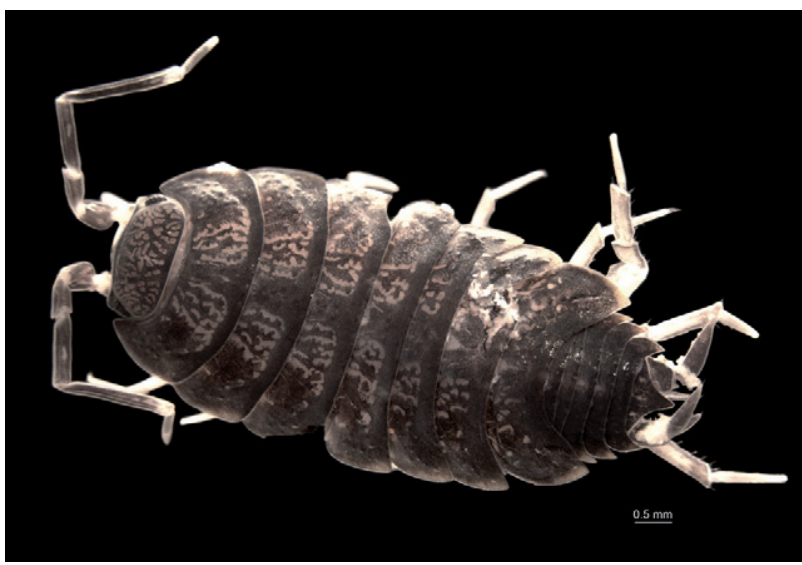

FIGURE 8

Porcellionides pruinosus, habitus, dorsal view (WAM C51824).

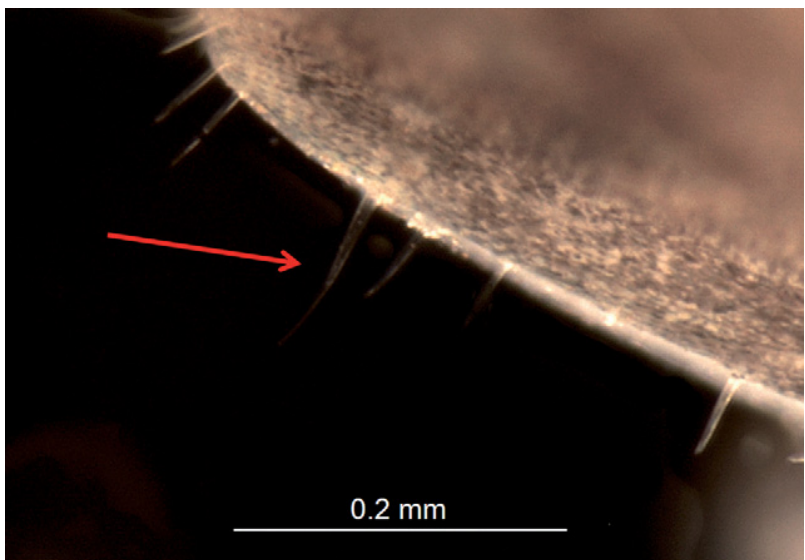

FIGURE $10 \quad$ Laevophiloscia yalgoonensis fourth pereonite dorsal view. Arrow: noduli lateralis (WAM C51821)

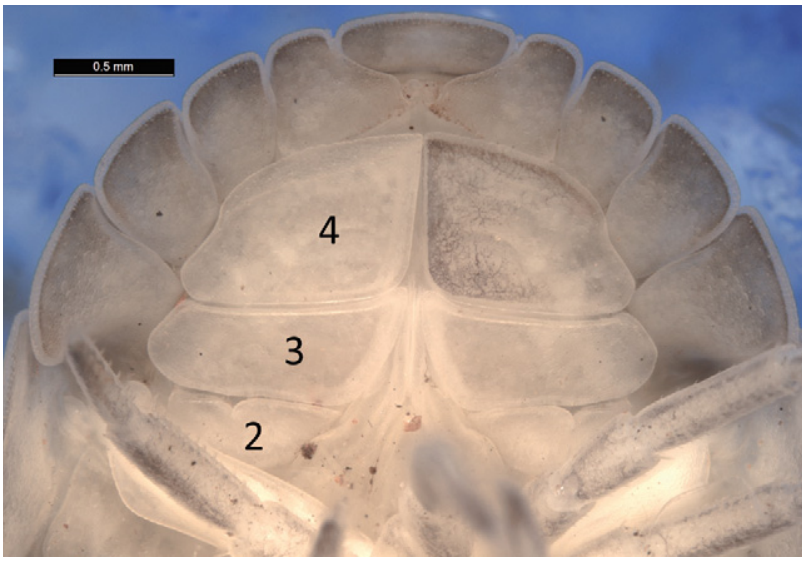

FIGURE 12

Buddelundia sp. 5, pleon, ventral view. Pleopod exopodites interlocking (2-4). Fourth pair overlapping fifth (WAM C51810). 


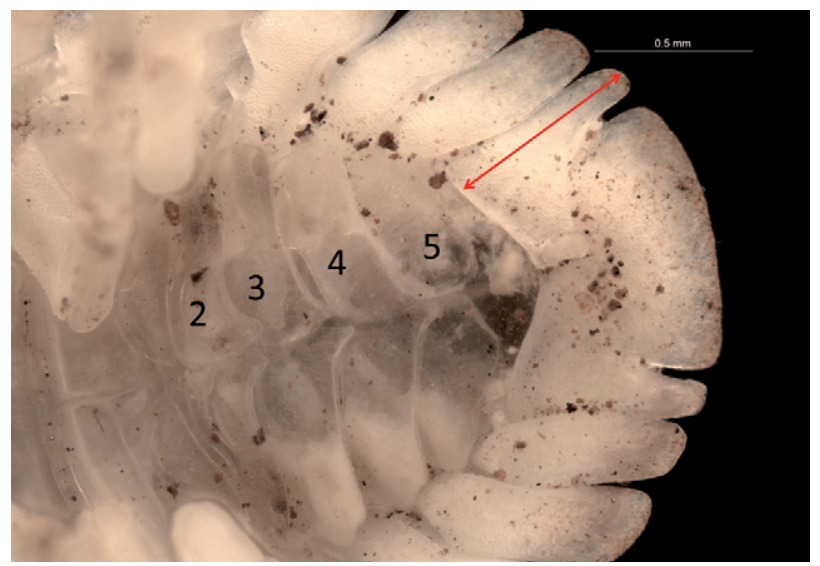

FIGURE 13 Armadillidae genus 3 sp. 1, pleon, ventral view. Pleopod exopodites non-interlocking (2-5). Arrow: uropod protopodite with distal part long and tapering. (WAM C51686).

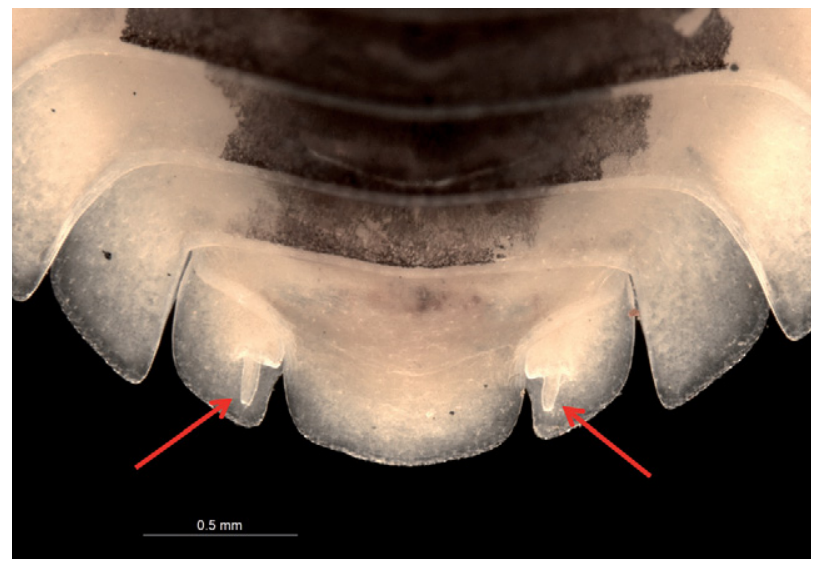

FIGURE 15

Armadillidae genus $1 \mathrm{sp} .1$, pleon dorsal, view. Arrows: uropod exopodites extending almost to the distal margin of the protopodite. (WAM C51817).

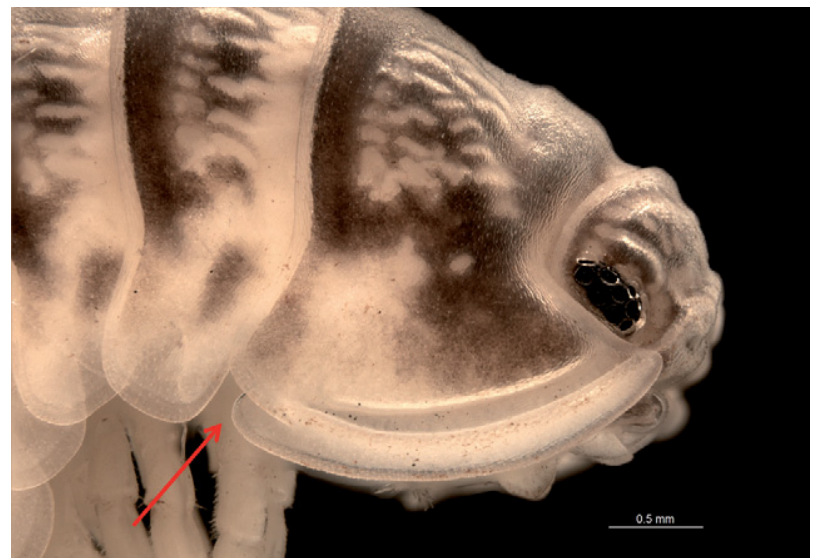

FIGURE 17
Buddelundia sp. 3, partial lateral view. Sulcus arcuatus prominent. Arrow: schisma on pereonite 1 (WAM C51741).

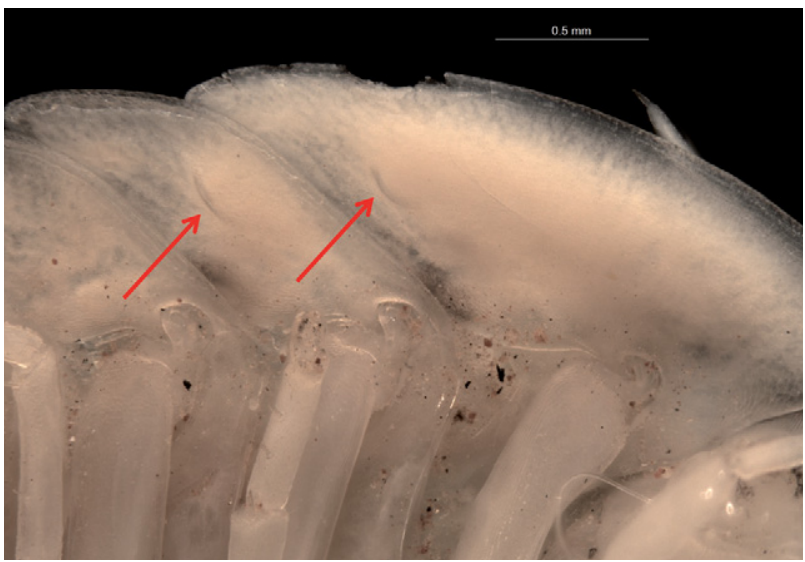

FIGURE 14

Armadillidae genus $1 \mathrm{sp} .1$, epimera 1 and 2, ventral view. Arrows: small rounded bumps (WAM C51817).

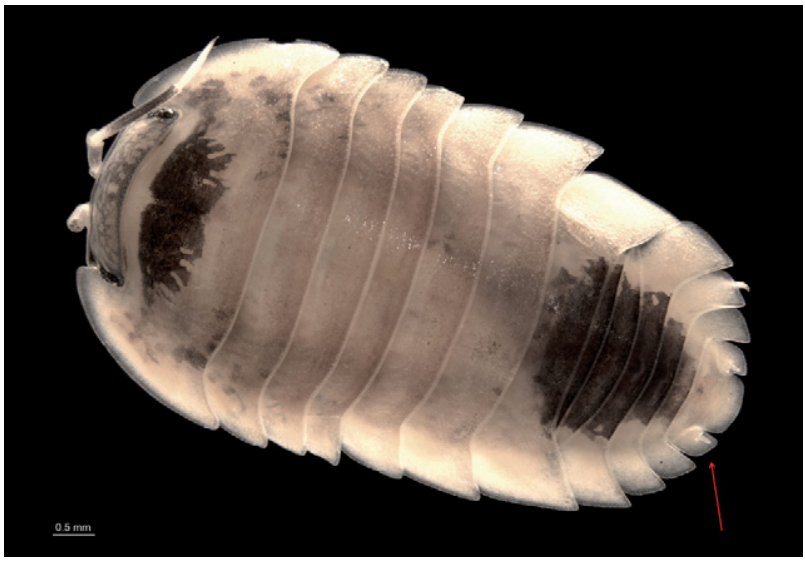

FIGURE 16

Armadillidae genus $1 \mathrm{sp.}$ 1, habitus, dorsal view (WAM C51817).

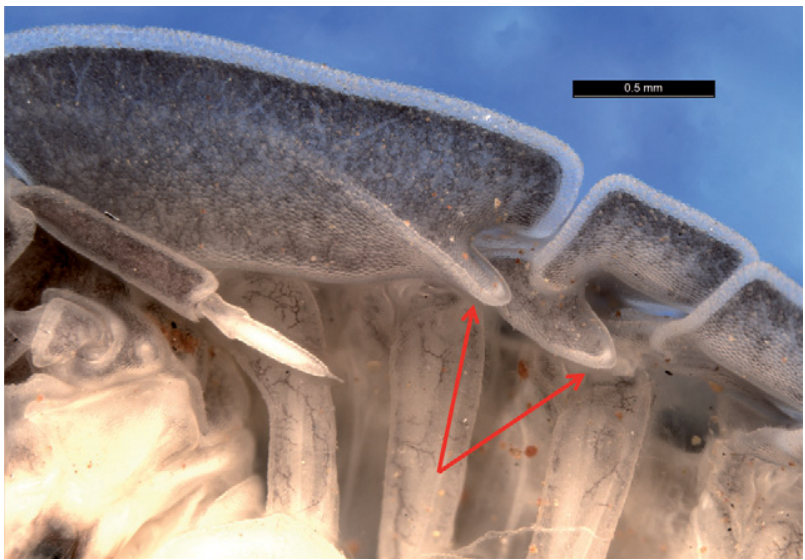

FIGURE 18

Barrowdillo pseudopyrgoniscus, pleonite, epimera 1 and 2 ventral view. Arrows: tooth-like lobes (WAM C51704). 


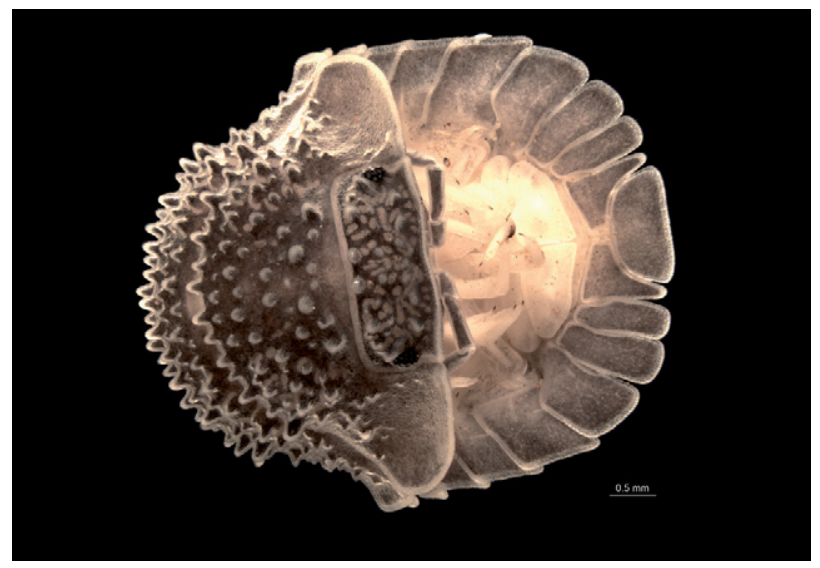

FIGURE 19

Barrowdillo pseudopyrgoniscus, horizontal epimera (WAM C51704).

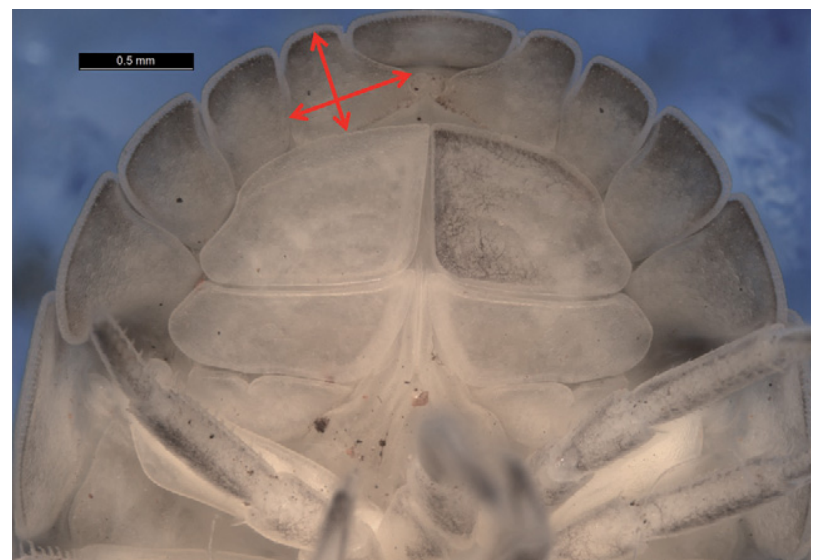

FIGURE 21

Buddelundia sp. 5, pleon, ventral view. Arrows: uropod protopodite not longer than broad and not tapering (WAM C51810).

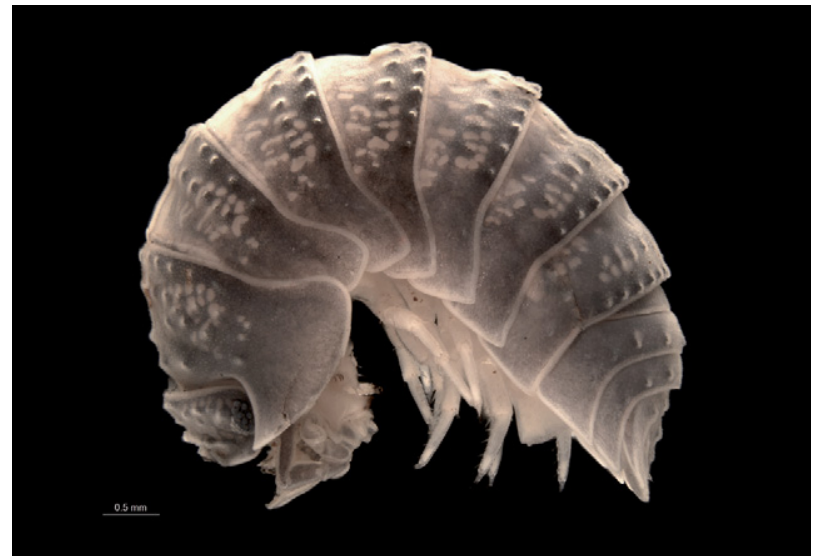

FIGURE 23

Armadillidae genus $2 \mathrm{sp} .1$, habitus, lateral view. Dorsal surface with shallow bumps and epimera tending horizontal at the distal margins (WAM C51818).

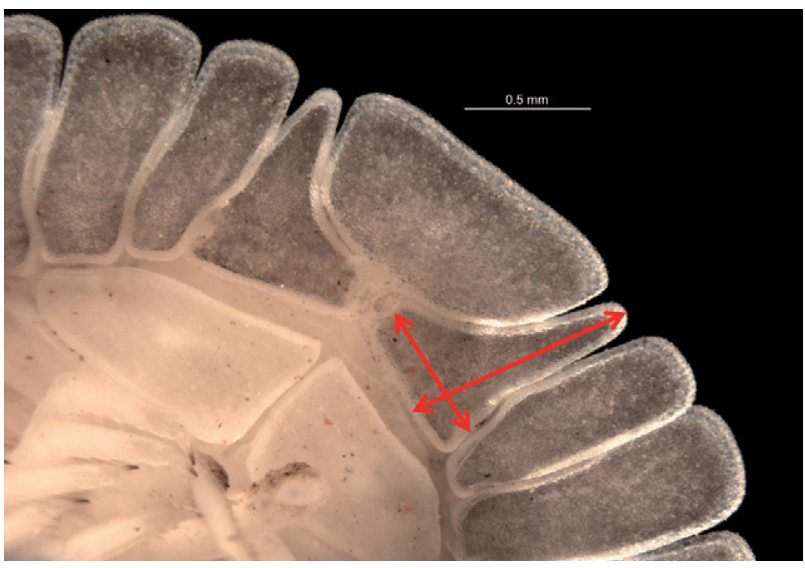

FIGURE 20 Barrowdillo pseudopyrgoniscus, pleon, ventral view. Arrows: uropod protopodite longer than broad and tapering (WAM C51704).

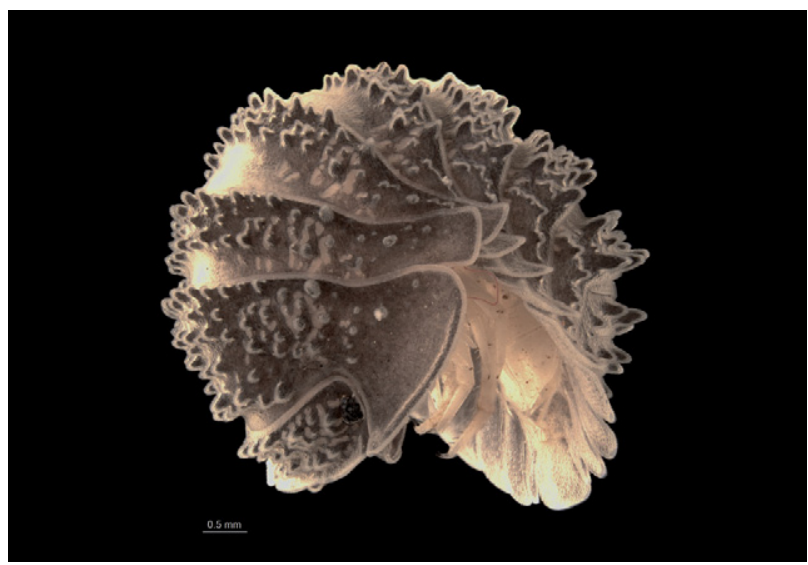

FIGURE 22 Barrowdillo pseudopyrgoniscus, habitus, lateral view (WAM C51704).

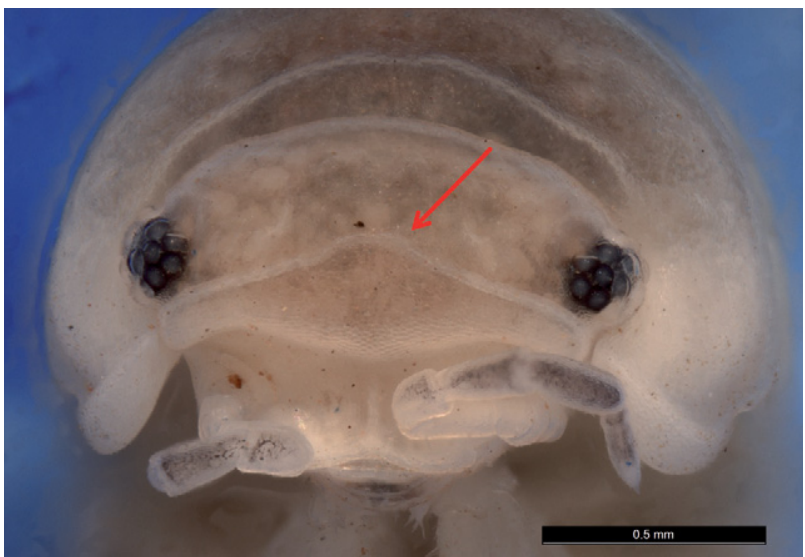

FIGURE 24

Buddelundia sp. 2, head and first pereonite, anterior view. Arrow: upper margin of frontal shield which is not divided by transverse groove (WAM C51771). 


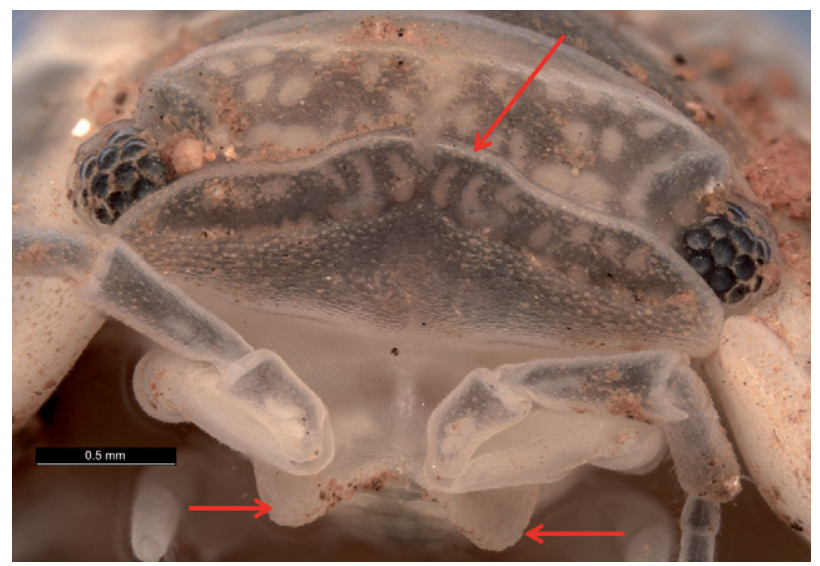

FIGURE 25

Buddelundia sp. 3, head and first pereonite, anterior view. Arrows: upper margin of frontal shield which is divided by transverse groove and protuberances above clypeus (WAM C51741).

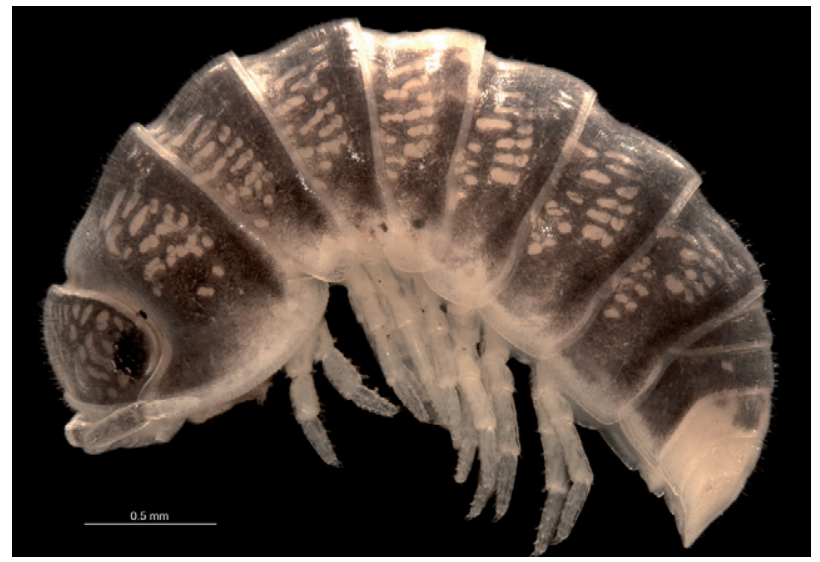

FIGURE 27 Buddelundia sp. 1, habitus, lateral view (WAM C51764).

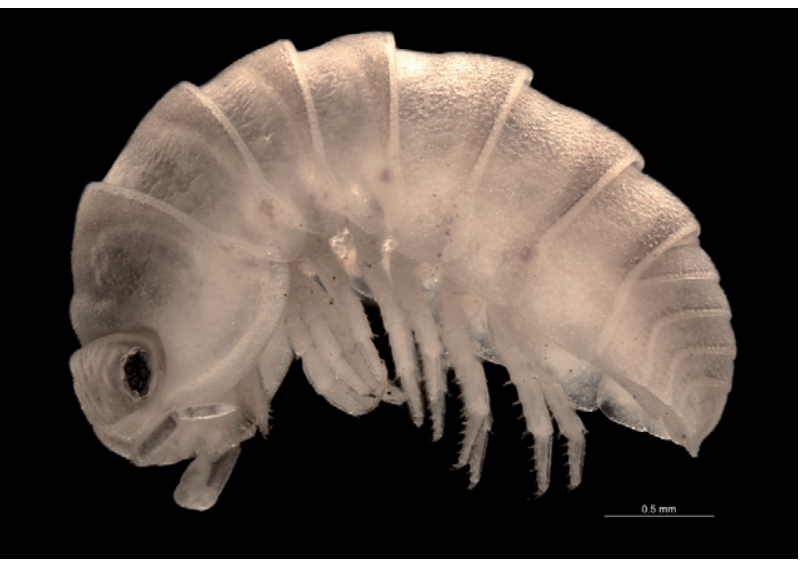

FIGURE 29

Buddelundia sp. 2, habitus, lateral view (WAM C51771).

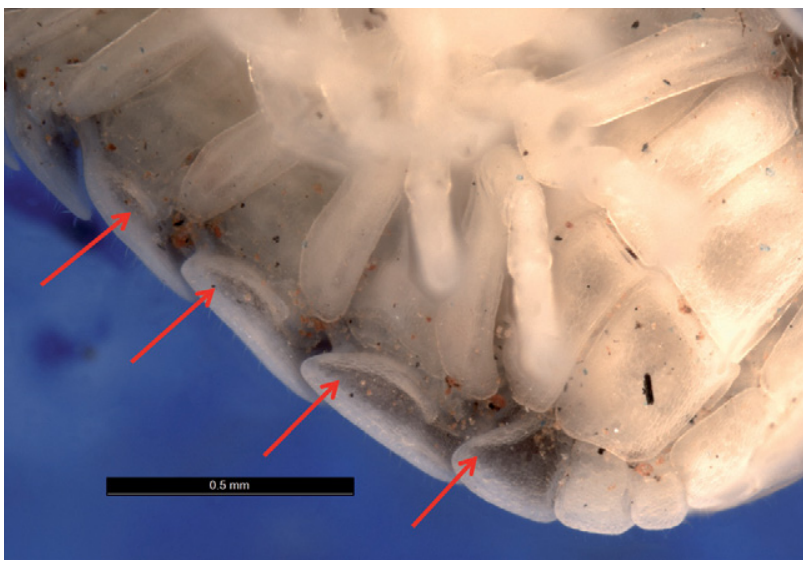

FIGURE 26

Buddelundia sp. 1, partial ventral view. Arrows: interlocking structures on pereonites 5-7 and pleonite 3 (WAM C51764).

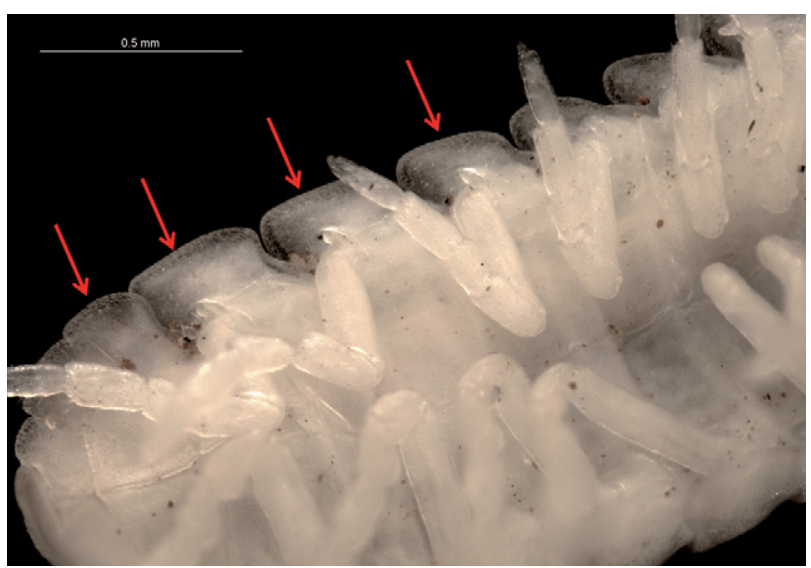

FIGURE 28

Buddelundia sp. 2, partial, ventral view. Arrows: interlocking structures absent on pereonites 5-7 and pleonite 3 (WAM C51771).

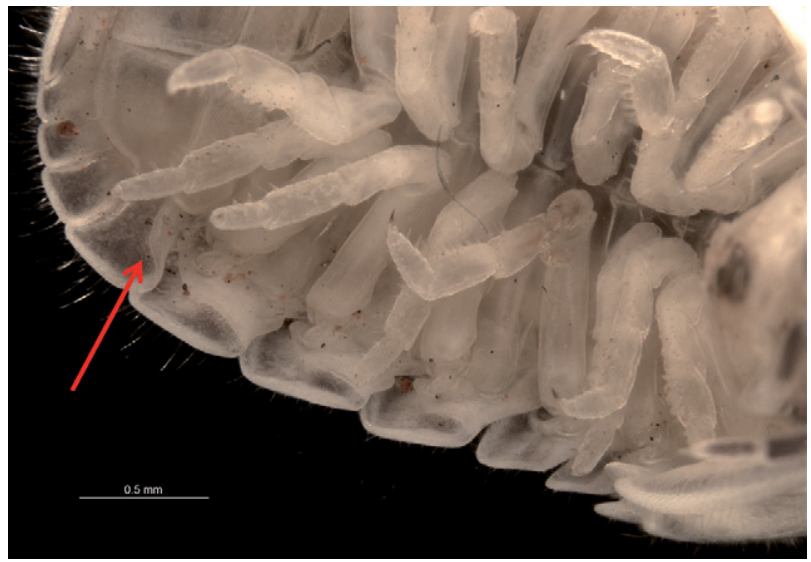

FIGURE 30

Buddelundia hirsuta, partial, ventral view with interlocking structures on pereonites 5-7 and pleonite 3 (arrow) (WAM C51708). 


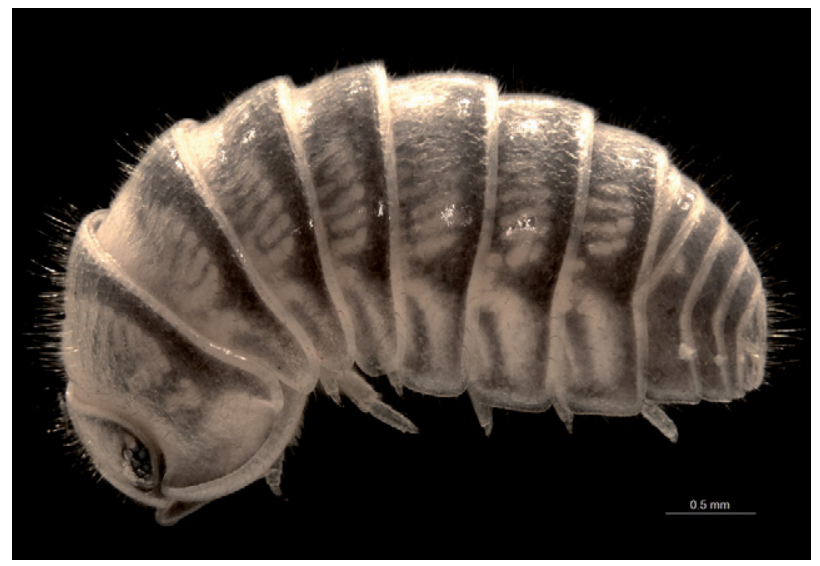

FIGURE $31 \quad$ Buddelundia hirsuta, habitus, lateral view (WAM C51708).

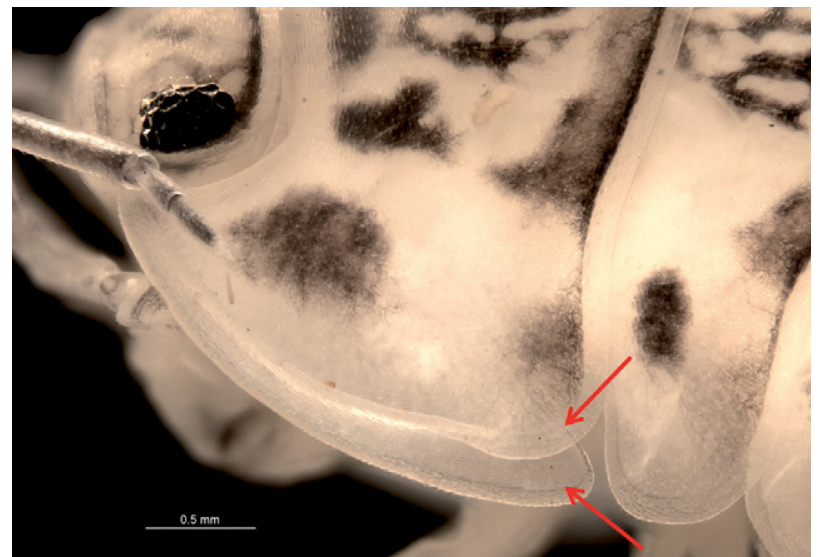

FIGURE 33

Buddelundia sp. 4, head and pereonite 1, lateral view with sulcus arcuatus absent. Arrows: schisma with inner lobe longer than outer (WAM C51767).

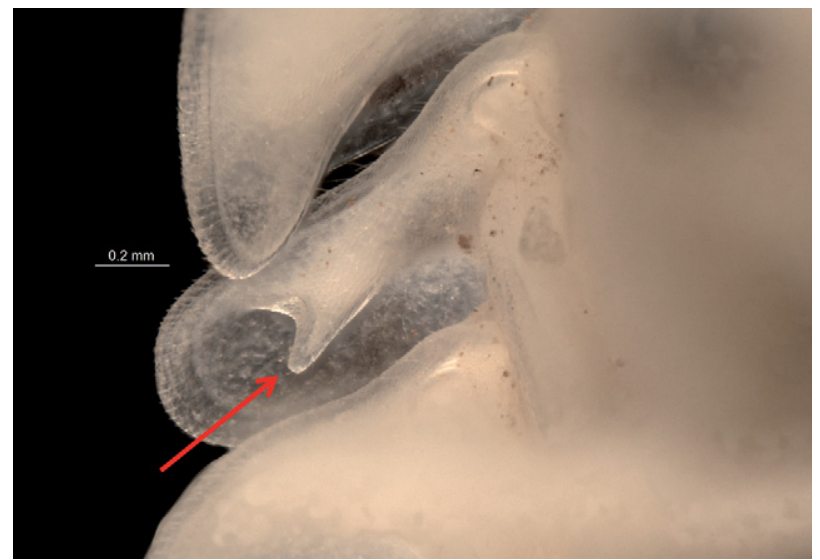

FIGURE 35

Buddelundia sp. 4, epimera of pereonite 2, ventral view. Arrow: large tooth-like lobe (WAM C51767).

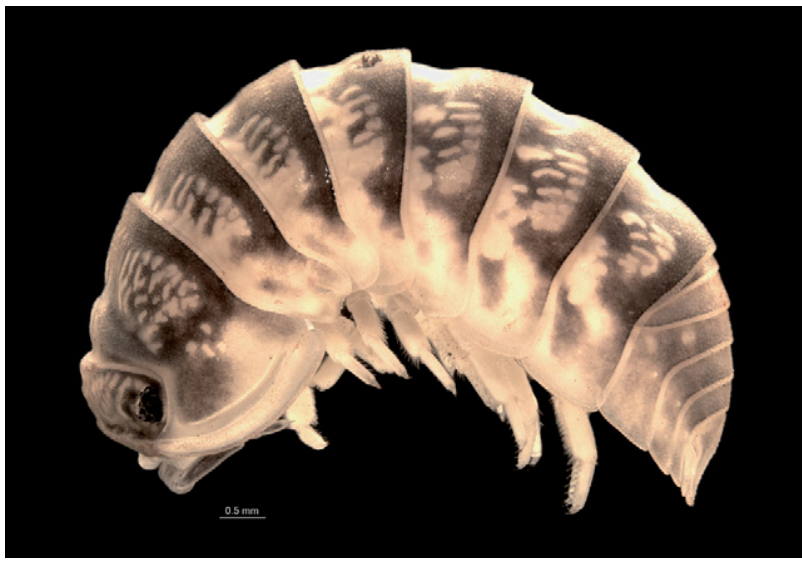

FIGURE 32 Buddelundia sp. 3, habitus, lateral view (WAM C51741)

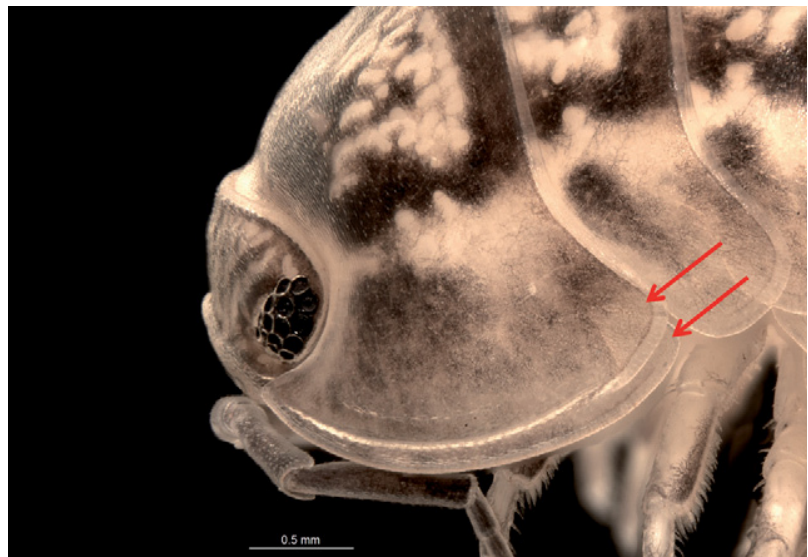

FIGURE 34

Buddelundia sp. 5, head and pereonite 1, lateral view with sulcus arcuatus indistinct. Arrows: schisma with inner lobe shorter than outer (WAM C51810)

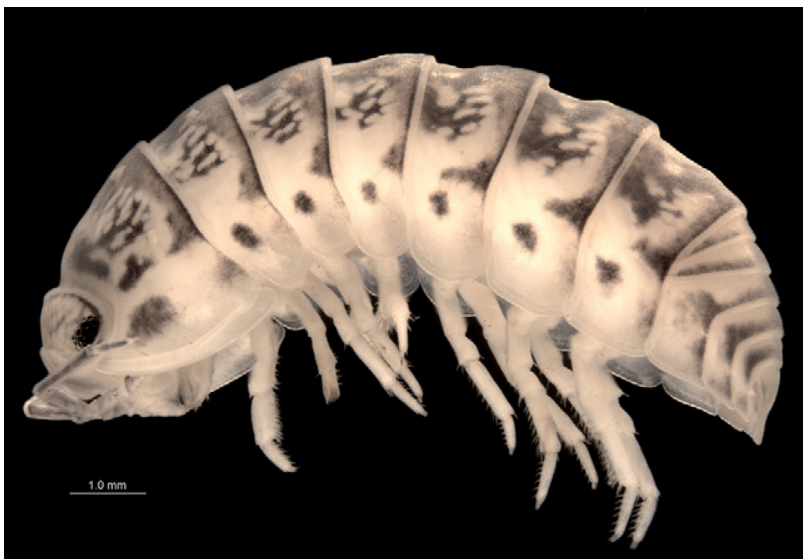

FIGURE 36 Buddelundia sp. 4, habitus, lateral view (WAM C51767) 


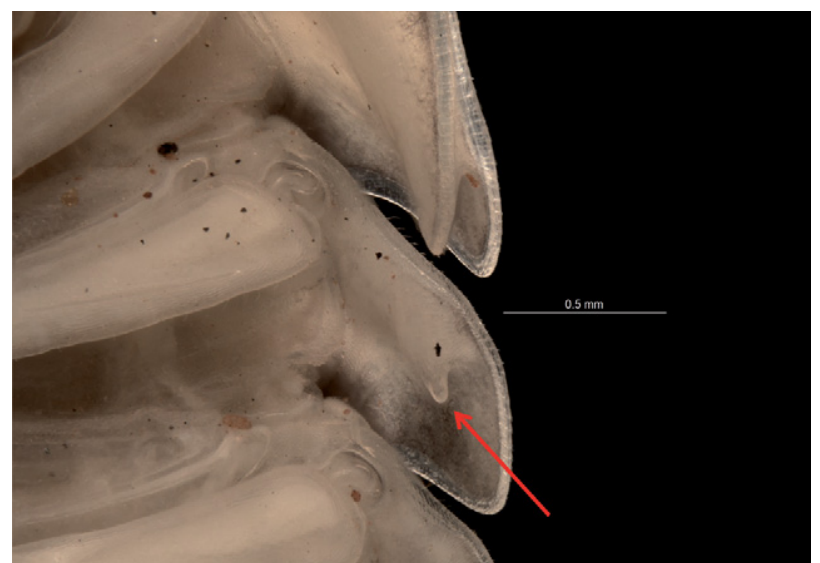

FIGURE 37

Buddelundia sp. 5, epimera of pereonite 2, ventral view. Arrow: small tooth-like lobe (WAM C51810).

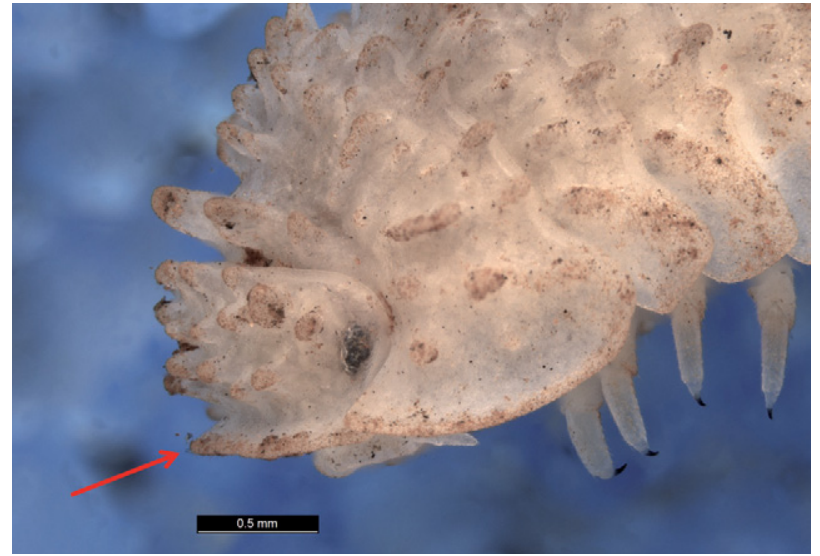

FIGURE 39

Armadillidae genus 3 sp. 1, head, lateral view. Arrow: frontal shield raised from vertex (WAM C51686).

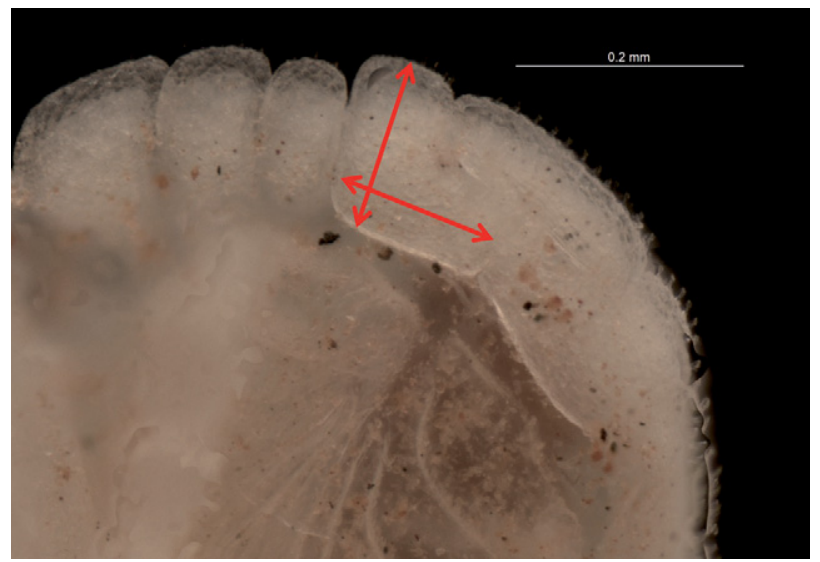

FIGURE 41

Armadillidae genus 4 sp. 2, pleon, ventral view. Arrow: uropod protopodite with distal part short and quadrangular, approximately equally wide as long (WAM C51695).

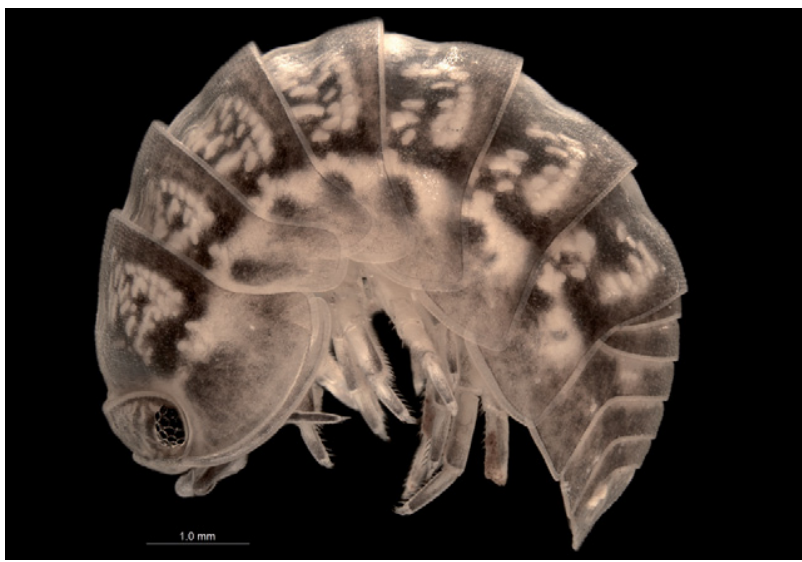

FIGURE 38 Buddelundia sp. 5, habitus, lateral view (WAM C51810).

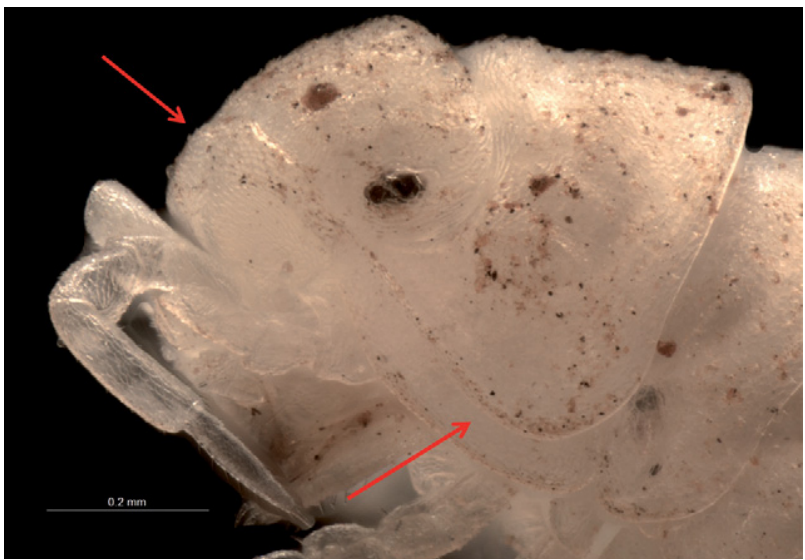

FIGURE $40 \quad$ Armadillidae genus 4 sp. 1, head, lateral view. Arrows: frontal shield not raised from vertex and lateral groove on pereonite 1 wide (WAM C51700).

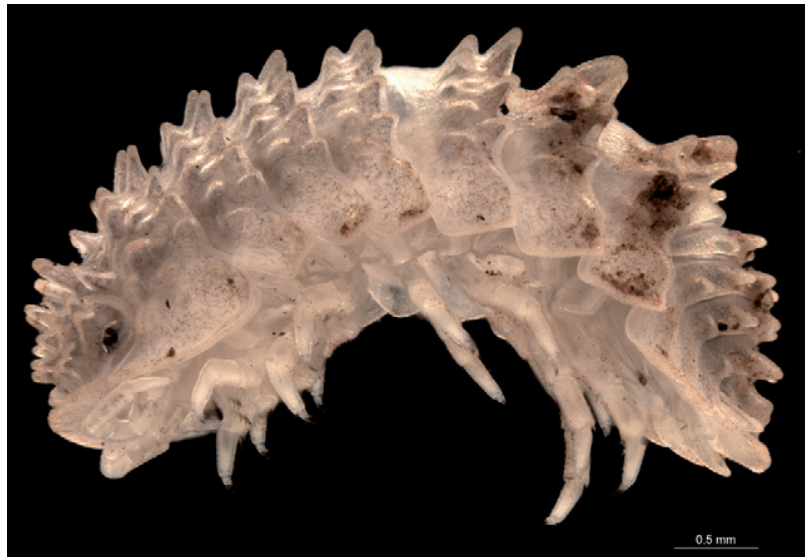

FIGURE 42

Armadillidae genus 3 sp. 1, habitus, lateral view. Dorsal surface with tubercules (WAM C51686). 


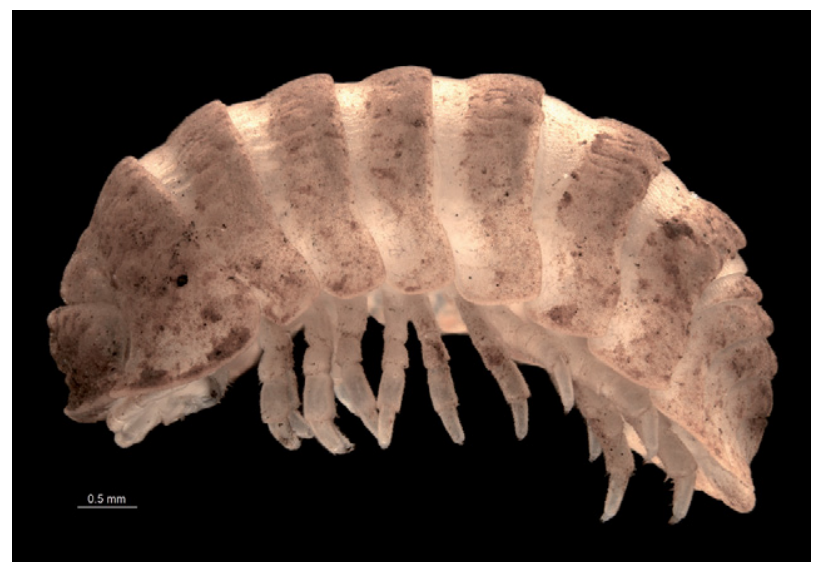

FIGURE 43 Armadillidae genus $3 \mathrm{sp.}$ 2, habitus, lateral view. Dorsal surface rough but with no distinct tubercles (WAM C51685)

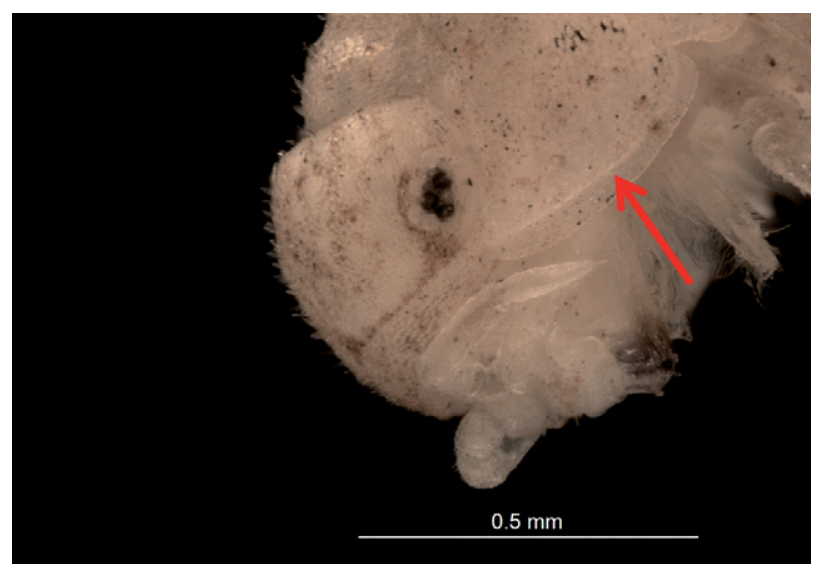

FIGURE 45

Armadillidae genus 4 sp. 2, partial lateral view. Dorsal surface with distinct setae. Arrow: lateral groove on pereonite 1 narrow (WAM C51695).

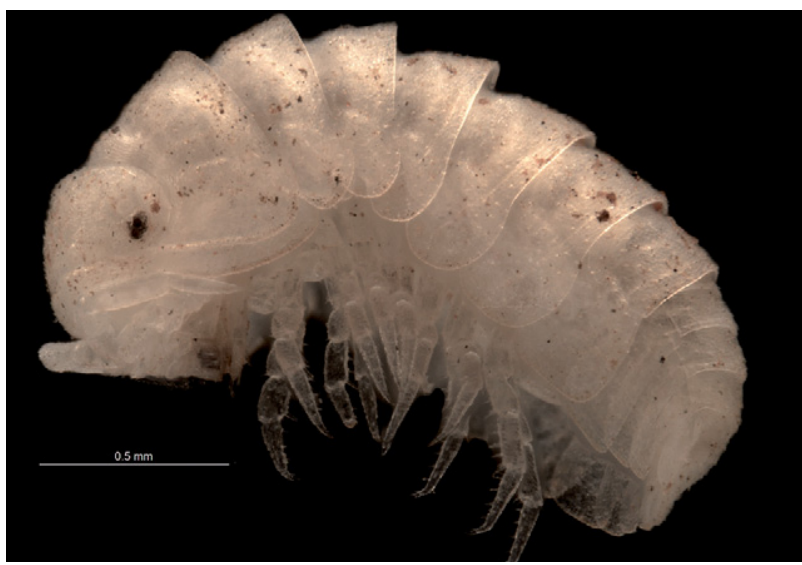

FIGURE 44

Armadillidae genus $4 \mathrm{sp} .1$, habitus, lateral view. Dorsal surface without distinct setae (WAM C51700).

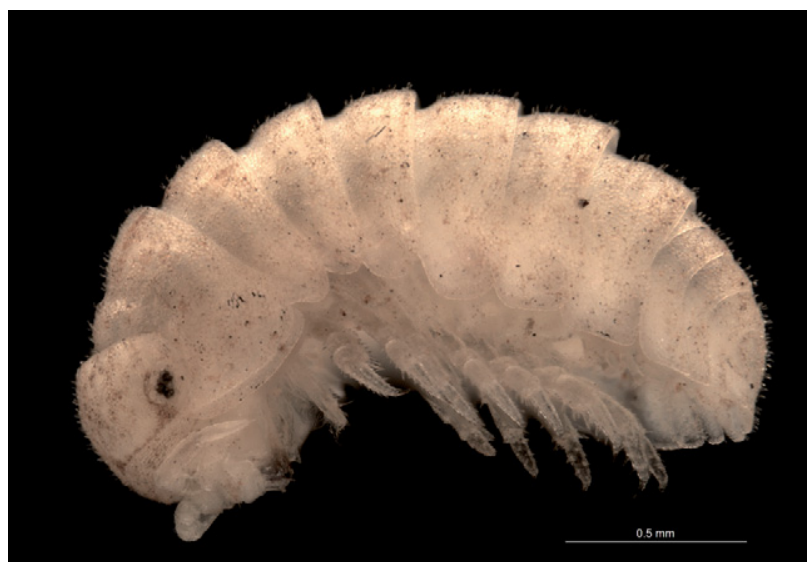

FIGURE $46 \quad$ Armadillidae genus 4 sp. 2, habitus, lateral view (WAM C51695). 


\section{LIST OFTHE SPECIES AND REMARKS}

Family Ligiidae Leach, 1831

Genus Ligia Fabricius, 1798

Ligia exotica Roux, 1828

Figure 1

\section{MATERIAL EXAMINED}

Australia: Western Australia: 1 , Pt. Gantheaume, Broome, ca. 1924 (WAM C1440).

\section{REMARKS}

This species was not collected during the present study but was included in the key because it was listed by Dalens (1993) from Barrow Island. The material from Barrow Island was not available for examination so the image included in the key is Ligia exotica from Broome. Dalens' identification requires confirmation since his description does not contain illustrations and was based on a single female specimen. Ligia exotica is a widely distributed tropical species (Dalens 1993). The principal diagnostic characters of this species are: uropod exopodites long, extending beyond the uropod protopodite; multi-articulate flagellum with more than 5 segments and the large eye consisting of more than 100 ommatidia. On Barrow Island the species is known from a single site (Figure 47), but is likely to be much more widespread.

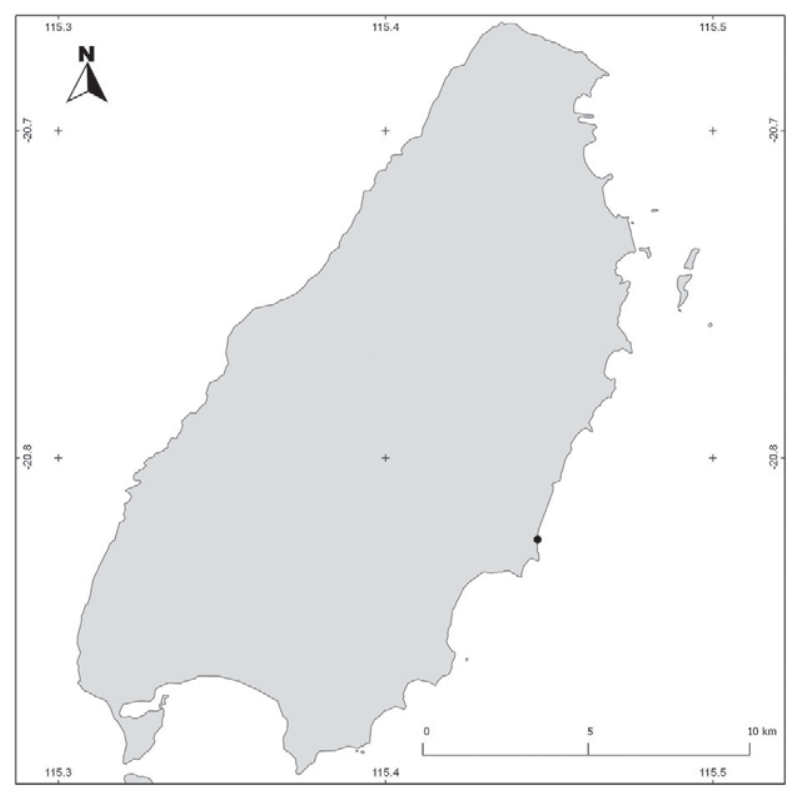

FIGURE 47

Distribution records of Ligia exotica and Olibrinus sp. on Barrow Island.

\section{Family Olibrinidae Budde-Lund, 1913}

Genus Olibrinus Budde-Lund, 1913

Olibrinus sp.

Figures 2, 3

\section{MATERIAL EXAMINED}

Australia: Western Australia: Barrow Island:

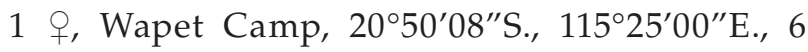
September 1991, W.F. Humphreys, B. Vine (WAM 127-91).

\section{REMARKS}

This species was not collected during the present study, but was included in the key because it was described in part by Dalens (1993). His identification was based on a single female and further studies are needed to confirm the status of this taxon. Its principal diagnostic characters are: habitus elongated; uropod exopodites long, extending beyond the uropod protopodite; long multi-articulate flagellum with more than 5 segments; and eye consisting of 5 ommatidia. Olibrinus sp. and Ligia exotica are known from the same single locality on Barrow Island (Figure 47).

Family Alloniscidae Schmidt, 2003

Genus Alloniscus Dana, 1854

Alloniscus pallidulus Budde-Lund, 1885

Figures 4, 6, 9

\section{MATERIAL EXAMINED}

Australia: Western Australia: Barrow Island: 1 , Site TPT, $20^{\circ} 46^{\prime} 52.49^{\prime \prime}$ S., $115^{\circ} 28^{\prime} 02.87^{\prime \prime}$ E., 15 March 2006, S. Callan, R. Graham, winkler sack (WAM C51826); 8 ô, Site CBH, 5 , 2049'29.76”'S., $115^{\circ} 26^{\prime} 47.19^{\prime \prime}$., 25 September 2006, S. Callan, K. Edwards, winkler sack (WAM C51827); 1 q, Site N27, 2049'29.76"S., 115²6'47.19"E., 6 May 2006, S. Callan, R. Graham (WAM C51828); 2 jิ, 2 , Site CBH, 2052'21.64"S., 115¹9'47.74"E., 15 March 2006, S. Callan, R. Graham (WAM C51829).

\section{REMARKS}

This is a widespread littoral species that occurs along the Western Australia coast and in parts of South-East Asia (Green et al. 1990). It has been collected from Rottnest Island (Bunn and Green 1982) and from the littoral zone of the ocean and from salt water coastal lagoons in the Jurien Bay area (Judd and Horwitz 2003). Its principal 


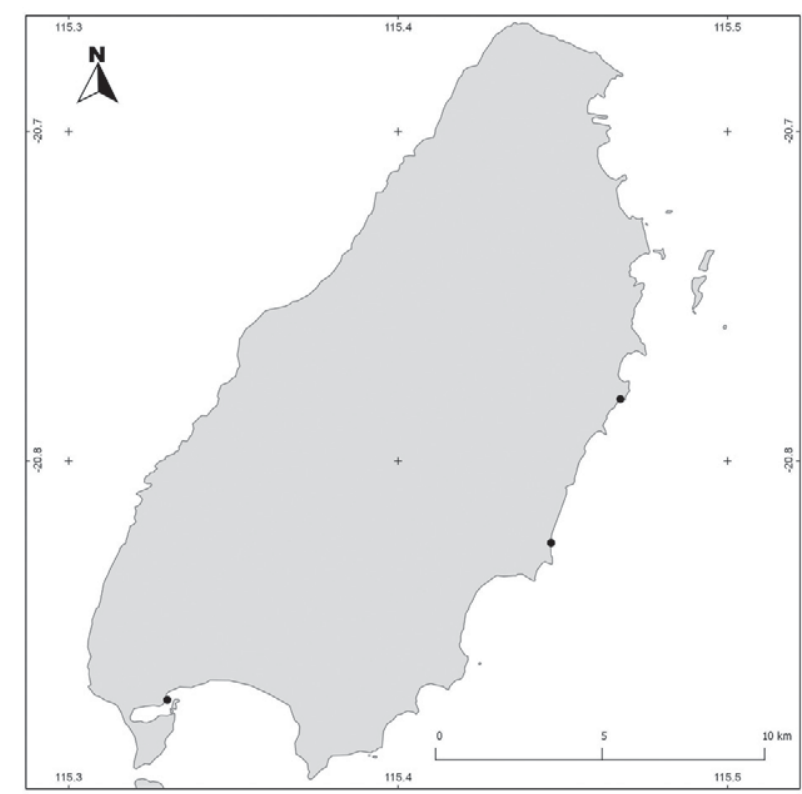

FIGURE 48
Distribution records of Alloniscus pallidulus on Barrow Island.

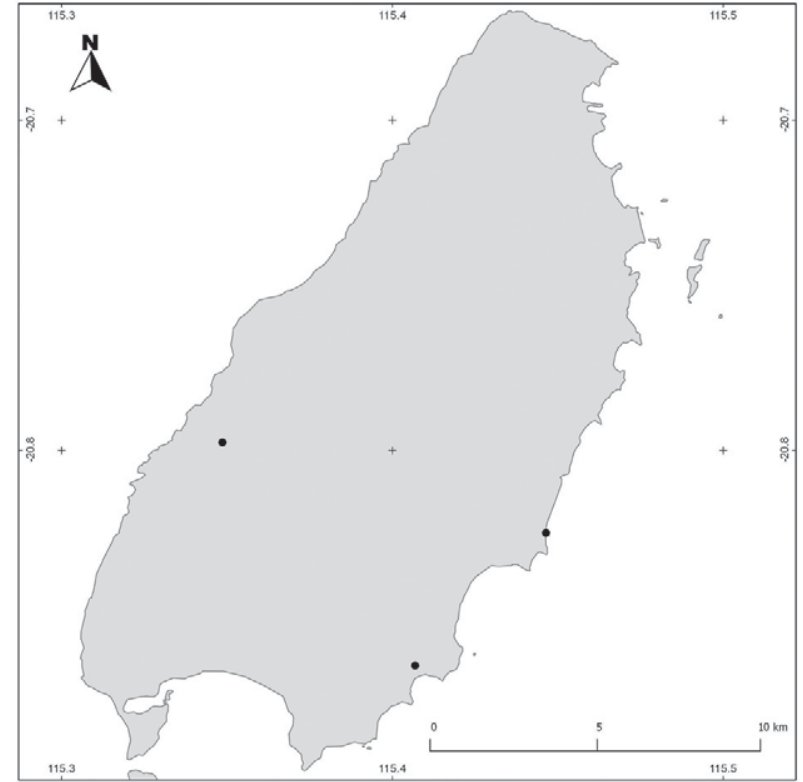

FIGURE 49

Distribution records of Laevophiloscia yalgoonensis on Barrow Island. diagnostic characters are: uropod exopodites long extending beyond the uropod protopodite; flagellum of second antenna 3 segmented; epimera of pleonites 3-5 long and tapered; and noduli laterales absent. The species was collected from the littoral zone at three locations on Barrow Island (Figure 48).

\section{Family Philosciidae Kinahan, 1857}

Genus Laevophiloscia Wahrberg, 1922

\section{Laevophiloscia yalgoonensis Wahrberg, 1922}

Figures 10, 11

\section{MATERIAL EXAMINED}

Australia: Western Australia: Barrow Island:

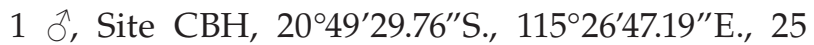
September 2006, S. Callan, K. Edwards, winkler sack (WAM C51820); 1 , Site N05, 2051'53.94”S., $115^{\circ} 24^{\prime 2} 24.75^{\prime \prime E}$., 6 May 2006, S. Callan, R. Graham (WAM C51821); 1 q, Site DMP, 2047'51"S., $115^{\circ} 20^{\prime} 55^{\prime \prime E}$.17 May 2005, S. Callan, hand collected (WAM C51822).

\section{REMARKS}

The species was originally described by Wahrberg (1922) from two semi-arid, inland localities, namely Yalgoo and Day Dawn (Lake Austin). The species was redescribed by Vandel (1973) from four coastal limestone caves, three near Jurien Bay and one in Augusta. However, neither description is complete by modern taxonomic standards or sufficiently illustrated for accurate species identification. The identification of the specimens in this study is based on that of Dalens (1993). The species is potentially widespread. Its principal diagnostic characters are: uropod exopodites long, extending beyond the uropod protopodite; flagellum of second antenna 3-segmented; noduli laterales present on pereonites; and epimera of pleonites 3-5 reduced. This species was collected from three sites in this study but is probably more widespread (Figure 49).

\section{Family Porcellionidae Brandt, 1831}

Genus Porcellionides Miers, 1877

Porcellionides pruinosus (Brandt, 1833)

Figures 7, 8

\section{MATERIAL EXAMINED}

Australia: Western Australia: Barrow Island: 3 juveniles, Site N01, 2049'35.41"S., 115²6'39.52"E., 6 May 2006, S. Callan, R. Graham, winkler sack (WAM C51823); 1 , Site N01a, 2049'34.11"S., $115^{\circ} 26^{\prime} 43.86^{\prime \prime}$ E., 1 May 2007, S. Callan, K. Edwards, hand collection (WAM C51824); 1 +, Site ACCZ1, 2049'34.57"S., $115^{\circ} 26^{\prime} 43.85^{\prime \prime}$ E., 8 March 2010, N. Gunawardene, C. Taylor, night hand collection (WAM C51825). 


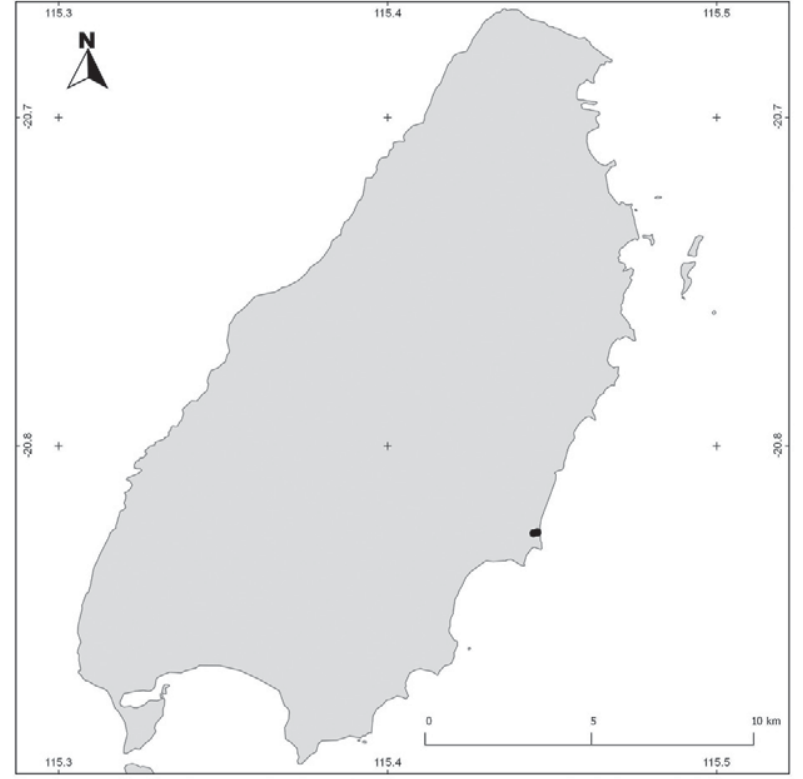

FIGURE 50
Distribution records of Porcellionides pruinosus on Barrow Island.

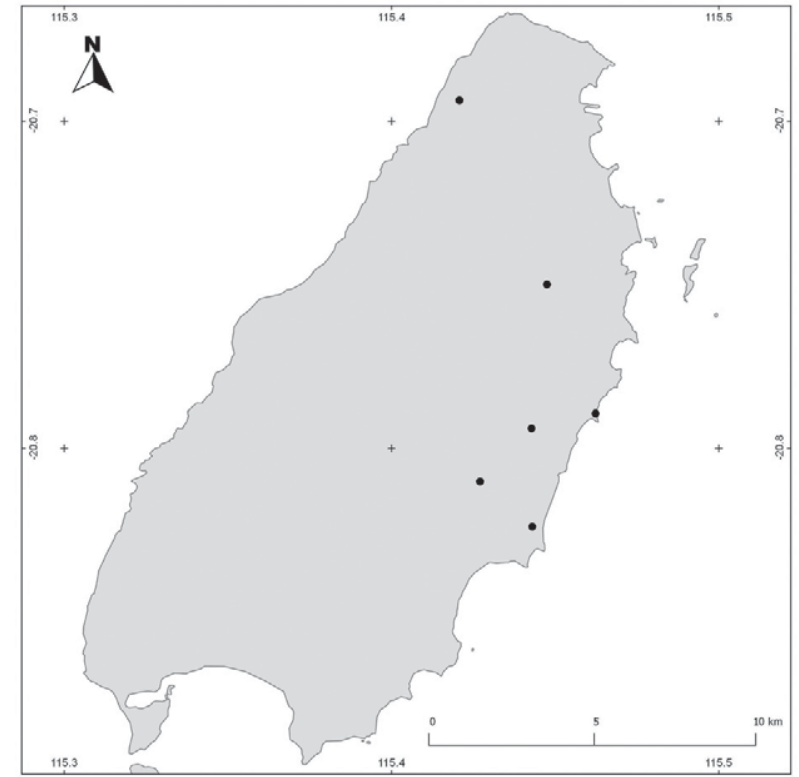

FIGURE 51

Distribution records of Barrowdillo pseudopyrgoniscus on Barrow Island.

\section{REMARKS}

This is an introduced, widespread and synanthropic species with its origin in the Mediterranean basin. It is possibly an early introduction into Western Australia. Its principal diagnostic characters are: uropod exopodites long extending beyond the uropod protopodite; flagellum of second antenna 2-segmented; head with small frontal lobes; and posterior margin of pereonite 1 convex. This species was collected from three sites on Barrow Island adjacent to human infrastructure (Figure 50).

\section{Family Armadillidae Brandt, 1831}

\section{Genus Barrowdillo Dalens, 1993}

\section{Barrowdillo pseudopyrgoniscus Dalens, 1993}

Figures 18, 19, 20, 22

\section{MATERIAL EXAMINED}

Australia: Western Australia: Barrow Island: 1 ${ }^{\lambda}$, Site N14, $20^{\circ} 48^{\prime} 36.60^{\prime \prime}$ S., $115^{\circ} 25^{\prime} 37.35^{\prime \prime}$ E., 1 May 2007, S. Callan, K. Edwards, hand collected (WAM

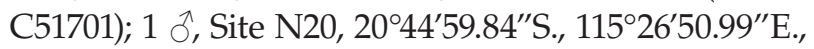
6 May 2006, S. Callan, R. Graham, pitfall trap (WAM C51702); 3 ㅇ, Site N03, 2049'26.33"S., $115^{\circ} 26^{\prime 3} 34.84^{\prime \prime E}$., 6 May 2006, S. Callan, R. Graham, winkler sack (WAM C51703); 1 ㅇ, 20 ${ }^{\circ} 47^{\prime} 38^{\prime \prime}$ S., $115^{\circ} 26^{\prime} 34^{\prime \prime}$ E., 24 April 2005, S. Callan (WAM C51704); $1 \delta^{\curvearrowright}$, Site HDDZI, $20^{\circ} 41^{\prime} 37.02^{\prime \prime}$ S., $115^{\circ} 25^{\prime} 14.70^{\prime \prime}$ E., 30

March 2012, N. Gunawardene, C. Taylor, wood bait (WAM C51705); 1 ㅇ, Site QAPZ1, 2047'21.75"S., $115^{\circ} 27^{\prime} 44.38^{\prime \prime E}$., 30 March 2012, N. Gunawardene, C. Taylor, night hand collection (WAM C51706).

\section{REMARKS}

This is the type and the only species of Barrowdillo currently described. It is known only from Barrow Island and the adjacent Varanus Island and may therefore be considered a shortrange endemic species (SRE) (Harvey 2002). Dalens' (1993) description is incomplete and not adequately illustrated for identification. A taxonomic revision is necessary, in particular because there are at least three undescribed species (S. Judd unpublished data) found in the western Pilbara region. Its principal diagnostic characters are: flagellum of second antenna 2 segmented; pleopod exopodites interlocking with pleopod 5 covered by pleopod 4; dorsal surface convex but with horizontal epimera; and schisma on posterior corner of pereonite 1 absent but with large tooth-like ventral lobe on pereonites 1 and 2. The distribution of this species on Barrow Island is shown in Figure 51.

\section{Genus Buddelundia Michaelsen, 1912}

\section{REMARKS}

Buddelundia was erected by Michaelsen (1912) and the type species, B. labiata (Budde-Lund, 1912) was designated by Taiti et al. (1998). As it is currently 
defined, Buddelundia comprises over 70 species in Western Australia, most of them undescribed and therefore the genus is in need of revision. The genus is particularly diverse in the Pilbara with many undescribed species (S. Judd, unpublished data). Its principal diagnostic characters are: pleopod exopodites interlocking with pleopod 5 covered by pleopod 4; dorsal surface convex with horizontal epimera and a schisma on posterior corner of pereonite 1 .

\section{Buddelundia hirsuta Dalens, 1992}

Figures 30, 31

\section{MATERIAL EXAMINED}

Australia: Western Australia: Barrow Island: 1 오 Site N05a, $20^{\circ} 51^{\prime} 53.94^{\prime \prime}$ S., $115^{\circ} 24^{\prime} 24.75^{\prime \prime}$ E., 1 May 2007, S. Callan, R. Graham, winkler Sack (WAM C51707); 1 ภ, 2 ㅇ, Site N05, 2051'58.11"S., $115^{\circ} 24^{\prime} 22.41^{\prime \prime}$ E., 6 May 2006, S. Callan, R. Graham (WAM C51708).

\section{REMARKS}

This species was described by Dalens (1992) based on two specimens collected from the entrance of a cave in Cape Range. Although the Barrow Island specimens match Dalens' description in most details, this species needs taxonomic revision against similar morphotypes in the genus. Buddelundia hirsuta is known only from Cape Range and Barrow Island. Its principal diagnostic characters are: frontal shield divided into upper and lower sections by a transverse groove; interlocking structures present on pereonites 2, 5, 6, and 7 and on pleonite 3; and dorsal surface covered in many long setae. This species has been collected at only one locality on the island (Figure 52).

\section{Buddelundia sp. 1}

Figures 26, 27

\section{MATERIAL EXAMINED}

Australia: Western Australia: Barrow Island: 2

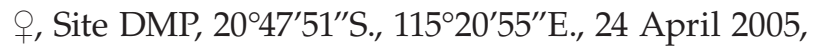
S. Callan, K. Edwards (WAM C51742); 15 specimens, Site GP6, 204ㄴ $4.71^{\prime \prime}$ S., $115^{\circ} 26^{\prime} 27.75^{\prime \prime}$., 15 March 2005, S. Callan, K. Edwards, winkler sack (WAM C51743); > 20 specimens, Site GP9, 204'59.18"S., $115^{\circ} 27^{\prime} 0.46^{\prime \prime}$ E., 15 March 2005, S. Callan, R. Graham, winkler sack (WAM C51744); 1 , Site N13, $20^{\circ} 50^{\prime} 32.41^{\prime \prime}$ S., $115^{\circ} 23^{\prime} 35.24^{\prime \prime}$ E., 6 May 2006, S. Callan, R. Graham, pitfall trap (WAM C51745); 2 ${ }^{\prime}$, Site N04, $20^{\circ} 43^{\prime} 29.29^{\prime \prime}$ S., $115^{\circ} 28^{\prime} 19.88^{\prime \prime}$ E., 6 May 2006, S. Callan, R. Graham, winkler sack (WAM C51746); Site N12, $20^{\circ} 49^{\prime} 54.75^{\prime \prime}$ S., $115^{\circ} 25^{\prime} 51.86^{\prime \prime}$.E.
6 May 2006, S. Callan, R. Graham, winkler sack (WAM C51747); 1 옹 Site N11, 2048'51.98"S., $115^{\circ} 22^{\prime} 32.15^{\prime \prime E}$., 6 May 2006, S. Callan, R. Graham, winkler sack (WAM C51748); 1 우, Site N15, $20^{\circ} 48^{\prime} 19.96^{\prime \prime}$ S., $115^{\circ} 25^{\prime} 52.36^{\prime \prime}$ E., 6 May 2006, S. Callan, R. Graham, winkler sack (WAM C51749); 1 , , Site N17, 204'52.63"S., 115²1'20.41"E., 6 May 2006, S. Callan, R. Graham, winkler sack (WAM C51750);

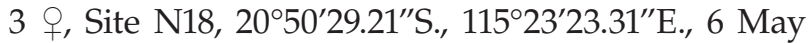
2006, S. Callan, R. Graham, winkler sack (WAM

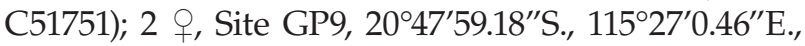
25 September 2006, S. Callan, R. Graham, winkler sack (WAM C51752); 3 ㅇ, Site N05a, 2051'58.11”S., $115^{\circ} 24^{\prime} 22.41^{\prime \prime}$ E., 1 May 2007, S. Callan, R. Graham, winkler sack (WAM C51753); 1 ㅇ, Site N07b, $20^{\circ} 49^{\prime} 5.63^{\prime \prime}$ S., $115^{\circ} 23^{\prime} 8.70^{\prime \prime}$ E., 1 May 2007, S. Callan, R. Graham, winkler sack (WAM C51754); 1 , Site N08, $20^{\circ} 46^{\prime} 44.90^{\prime \prime}$ S., $115^{\circ} 27^{\prime} 43.34^{\prime \prime}$ E., 1 May 2007, S. Callan, K. Edwards, winkler sack (WAM

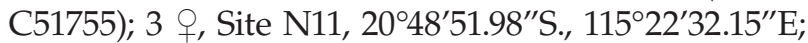
S. Callan, K. Edwards, winkler sack (WAM C51756); >20 specimens, Site N14, 20 48'36.60"S., $115^{\circ} 25^{\prime} 37.35^{\prime \prime}$ E., 1 May 2007, S. Callan, K. Edwards, winkler sack (WAM C51757); 8 specimens, Site N15, $20^{\circ} 48^{\prime} 19.96^{\prime \prime}$ S., $115^{\circ} 25^{\prime} 52.36^{\prime \prime}$ E., 1 May 2007, S. Callan, K. Edwards, winkler sack (WAM C51758); 2 , Site N16, 2047'47.82"S., 115²1'10.22"E., 1 May 2007, S. Callan, K. Edwards, winkler sack (WAM C51759);

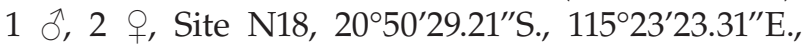
1 May 2007, S. Callan, K. Edwards, pitfall trap (WAM C51760); 5 ㅇ, Site N22, 2049'54.98"S., $115^{\circ} 25^{\prime} 13.29^{\prime \prime}$ E., 1 May 2007, S. Callan, K. Edwards, winkler sack (WAM C51761); 6 specimens, Site N23, $20^{\circ} 49^{\prime} 9.10^{\prime \prime}$ S., $115^{\circ} 23^{\prime} 39.73^{\prime \prime}$ E., 1 May 2007, S. Callan,

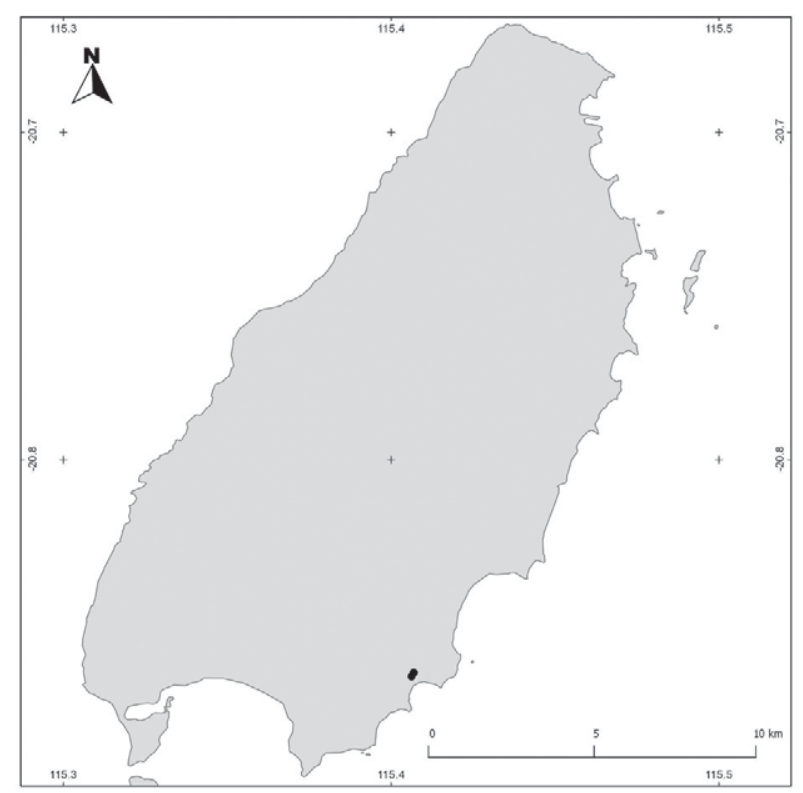

FIGURE 52
Distribution records of Buddelundia hirsuta on Barrow Island. 


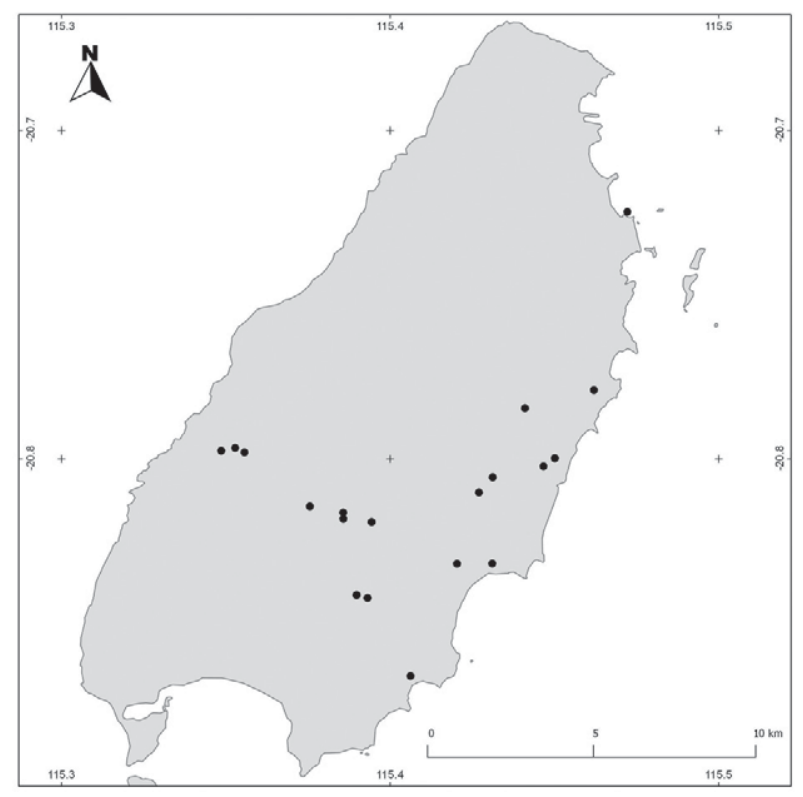

FIGURE 53

Distribution records of Buddelundia sp. 1 on Barrow Island.

K. Edwards, winkler sack (WAM C51762); 1 , , Site 105, 20 $48^{\prime} 08^{\prime \prime}$ S., $115^{\circ} 26^{\prime} 48^{\prime \prime}$ E., 17 May 2005, S. Callan, winkler sack (WAM C51763); > 20 specimens, Site N07a, $20^{\circ} 48^{\prime} 58.73^{\prime \prime S}$., $115^{\circ} 23^{\prime} 8.57^{\prime \prime}$ E., 1 May 2007, S. Callan, K. Edwards, winkler sack (WAM C51764).

\section{REMARKS}

This is an undescribed species characterised by: frontal shield not divided into upper and lower sections by a transverse groove; interlocking lobate structures present on the ventral surface of the epimera of pereonites 5-7 and pleonite 3; posterior margin of the first epimera straight (not angled backwards) and outer lobe of the schisma truncate making the inner lobe clearly visible and much longer than the outer lobe in lateral view; dorsal surface covered with short setae; the animal has a glossy brown appearance with cream-coloured telson and uropods. This species is probably also found in the western Pilbara (S. Judd unpublished data) but a complete revision of all material is needed to confirm conspecifity. It appears relatively widely distributed on Barrow Island (Figure 53).

\section{Buddelundia sp. 2}

Figures $24,28,29$

\section{MATERIAL EXAMINED}

Australia: Western Australia: Barrow Island:

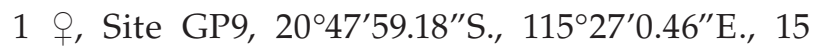
March 2006, S. Callan, R. Graham, pitfall trap

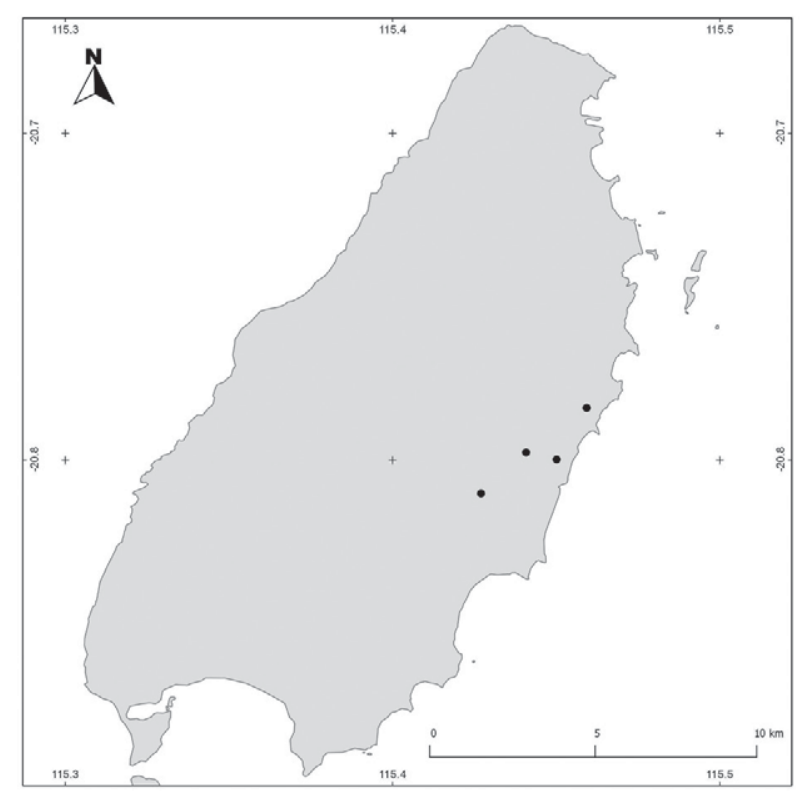

FIGURE 54

Distribution records of Buddelundia sp. 2 on Barrow Island.

(WAM C51769); 1 q, Site GP4, 2047'2.70"S., $115^{\circ} 27^{\prime} 33.54^{\prime \prime}$ E., 25 September 2006, S. Callan, R. Graham, pitfall trap (WAM C51770); 1 \%, Site N14, $20^{\circ} 48^{\prime} 36.60^{\prime \prime}$ S., $115^{\circ} 25^{\prime} 37.35^{\prime \prime}$ E., 1 May 2007, S. Callan, K. Edwards, pitfall trap (WAM C51771); 1 ㅇ, Site GP4, 2047'2.70"S., 115²7'33.54"E., 16 March 2006, S. Callan, R. Graham, winkler sack (WAM C51772); 1 , Site GP7, $20^{\circ} 47^{\prime} 51.40^{\prime \prime}$ S., $115^{\circ} 26^{\prime} 26.89^{\prime \prime}$ E., 15 March 2006, S. Callan, R. Graham, pitfall trap (WAM C51773).

\section{REMARKS}

This is an undescribed species distinguished by: frontal shield not divided into upper and lower sections by a transverse groove; interlocking lobate structures absent on the ventral surface of the epimera of pereonites 5-7 and pleonite 3; and dorsal surface without setae. No males were present in the material and more material is needed for a comprehensive morphological assessment. The species has only been found at four sites on the eastern part of the island and is considered a potential SRE species (Figure 54).

\section{Buddelundia sp. 3}

Figures 17, 25, 32

\section{MATERIAL EXAMINED}

Australia: Western Australia: Barrow Island: 1

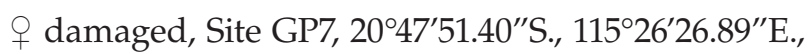
25 September 2006, S. Callan, R. Graham, 
hand collected (WAM C51709); 1 ㅇ, Site GP9, $20^{\circ} 47^{\prime} 59.18^{\prime \prime}$ S., $115^{\circ} 27^{\prime} 0.46^{\prime \prime}$.', 25 September 2006, S. Callan, R. Graham, hand collected (WAM C51710); 1 ㅇ, 2049'43"S., $115^{\circ} 26^{\prime} 36^{\prime \prime}$ E., 1 May 2005 (WAM

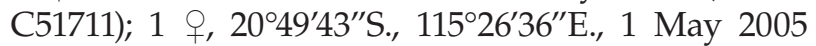
(WAM C51712); 1 ô, Site GPX, 2047'45.203"S., $115^{\circ} 27^{\prime} 8.39^{\prime \prime E}$., 15 March 2006, S. Callan, R. Graham, pitfall trap (WAM C51713); 1 , Site GP9, $20^{\circ} 47^{\prime} 59.18^{\prime \prime}$ S., $115^{\circ} 27^{\prime} 0.46^{\prime \prime}$ E., 15 March 2006, S. Callan, R. Graham, pitfall trap (WAM C51714); 1

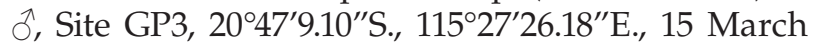
2006, S. Callan, R. Graham, pitfall trap (WAM

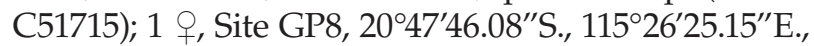
15 March 2006, S. Callan, R. Graham (WAM

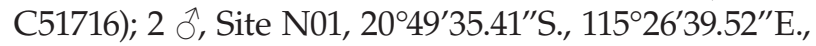
6 May 2006, S. Callan, R. Graham, hand collected (WAM C51717); 1 ก, 1 ㅇ, Site N04, 2043'29.29"S., $115^{\circ} 28^{\prime} 19.88^{\prime \prime}$ E., 6 May 2006, S. Callan, R. Graham, hand collected (WAM C51718); 3 万, 2 ㅇ, Site N06, $20^{\circ} 47^{\prime} 51.13^{\prime \prime}$ S., $115^{\circ} 25^{\prime} 57.60^{\prime \prime}$ E., 6 May 2006, S. Callan, R. Graham, pitfall trap (WAM C51719); 4 ऽ, 3 ㅇ, Site N08, 2046'44.90"S., $115^{\circ} 27^{\prime} 43.34^{\prime \prime}$ E., 6 May 2006, S. Callan, R. Graham, pitfall trap (WAM C51720); 1

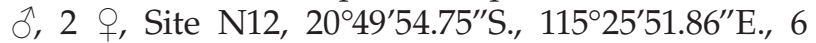
May 2006, S. Callan, R. Graham, Hand Collected (WAM C51721); $2 \delta^{\hat{O}}$, Site N15, 2048'19.960"S., $115^{\circ} 25^{\prime} 52.36^{\prime \prime E}$., 6 May 2006, S. Callan, R. Graham, pitfall trap (WAM C51722); 1 $\hat{\text {, }} 2$ 우, Site N26, 2049'1.22"S., 115²6'6.32"E., 6 May 2006, S. Callan, R. Graham, pitfall trap (WAM C51723); 1 $\widehat{\alpha}$, Site N01a, $20^{\circ} 49^{\prime} 34.12^{\prime \prime}$ S., $115^{\circ} 26^{\prime} 43.86^{\prime \prime}$ E., 1 May 2007, S. Callan, R. Graham, pitfall trap (WAM C51724); 1 , Site N03, 2049'26.33"S., $115^{\circ} 26^{\prime} 34.84^{\prime \prime}$ E., 1 May 2007, S. Callan, R. Graham, hand collected (WAM C51725); 2 O, 2 ㅇ, Site N04b, $20^{\circ} 43^{\prime} 43.85^{\prime \prime}$ S., $115^{\circ} 28^{\prime} 22.60^{\prime \prime}$ E., 1 May 2007, S. Callan, R. Graham, pitfall trap

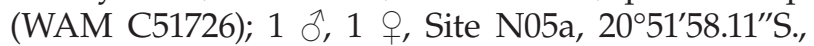
$115^{\circ} 24^{\prime} 22.41^{\prime \prime}$ E., 1 May 2007, S. Callan, K. Edwards, pitfall trap (WAM C51727); 2 के, Site N08, $20^{\circ} 46^{\prime} 44.90^{\prime \prime}$ S., $115^{\circ} 27^{\prime} 43.34^{\prime \prime}$ E., 1 May 2007, S. Callan, K. Edwards, pitfall trap (WAM C51728); 2 o, 1 ㅇ, Site N12, 2049'54.75'S., $115^{\circ} 25^{\prime} 51.86^{\prime \prime}$ E., 1 May 2007, S. Callan, K. Edwards, pitfall trap (WAM C51729); 1 ó, Site N15, $20^{\circ} 48^{\prime} 19.960^{\prime \prime}$ S., $115^{\circ} 25^{\prime} 52.36^{\prime \prime}$ E., 1 May 2007, S. Callan, K. Edwards, pitfall trap (WAM C51730); 1 ㅇ, Site N26, 2049'1.22"S., 115²6'6.32"E., 1 May 2007, S. Callan, K. Edwards, pitfall trap (WAM C51731); 1 Oे, Site GTPZ1, 204'40.20"S., $115^{\circ} 26^{\prime} 47.10^{\prime \prime E}$., 30 March 2005, N. Gunawardene, C. Taylor, Wood bait (WAM C51732); 1 गे, Site GTPZ1, $20^{\circ} 47^{\prime} 39.95^{\prime \prime}$ S., $115^{\circ} 26^{\prime} 48.38^{\prime \prime}$ E., 30 March 2005, N. Gunawardene, C. Taylor, night hand collection

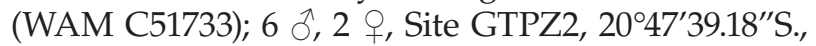
$115^{\circ} 27^{\prime} 11.77^{\prime \prime E}$., 30 March 2005, N. Gunawardene, C. Taylor, barrier pitfall trap (WAM C51734); 1 juvenile, Site GTPZ1, 2047'37.57"'S., 115²7'13.06"E., 30 March 2005, N. Gunawardene, C. Taylor, litter sample (WAM C51735); 5 ○े, 4 ㅇ, Site GTPZ1, 204'10.33"S., $115^{\circ} 27^{\prime} 28.52^{\prime \prime}$ E., 30 March 2005, N. Gunawardene, C.
Taylor, pitfall trap (WAM C51736); 1 , Site QAPZ1, $20^{\circ} 47^{\prime} 21.72^{\prime \prime}$., $115^{\circ} 27^{\prime} 44.38^{\prime \prime}$ E., 30 March 2005, N. Gunawardene, C. Taylor, night hand collection (WAM C51737); 1 ㅇ, Site WAPV2, 204'33.88"S., $115^{\circ} 28^{\prime 2} 23.95^{\prime \prime}$ E., 30 March 2005, N. Gunawardene, C. Taylor, window trap (WAM C51738); 2 0,2 , Site N03, 2049'26.33"S., $115^{\circ} 26^{\prime} 34.84^{\prime \prime}$ E., 6 May 2006, S. Callan, R. Graham (WAM C51739); 2 ô, Site GP6, $20^{\circ} 47^{\prime} 4.71^{\prime \prime}$ S., $115^{\circ} 26^{\prime} 27.75^{\prime \prime E}$., 25 September 2006 (WAM C51740); 4 o’, 2 +, Site N14, 2048'36.60"S., $115^{\circ} 25^{\prime} 37.35^{\prime \prime}$ E., 6 May 2006, S. Callan, R. Graham, pitfall trap (WAM C51741).

\section{REMARKS}

This is an undescribed species that occurs throughout the coastal parts of the western Pilbara (S. Judd unpublished data). The principal diagnostic characters are: frontal shield divided into upper and lower sections by a transverse groove; prominent sulcus arcuatus on pereonite 1; pleonite 3 without interlocking lobes; protuberances above the clypeus in males; and outer lobe of the schisma on the posterior corner of pereonite 1 slightly projected backwards and longer than inner lobe. The species shows affinities with B. bipartita Budde-Lund, 1912 occurring between Denham and Geraldton, $B$. cinerascens Budde-Lund, 1912 from Rottnest Island and B. inaequalis Budde-Lund, 1912 from Fremantle. All these species need to be revised in detail to obtain a better understanding of their taxonomic status and distribution. Buddelundia sp. 3 appears relatively common and widely distributed on the eastern part of the island (Figure 55).

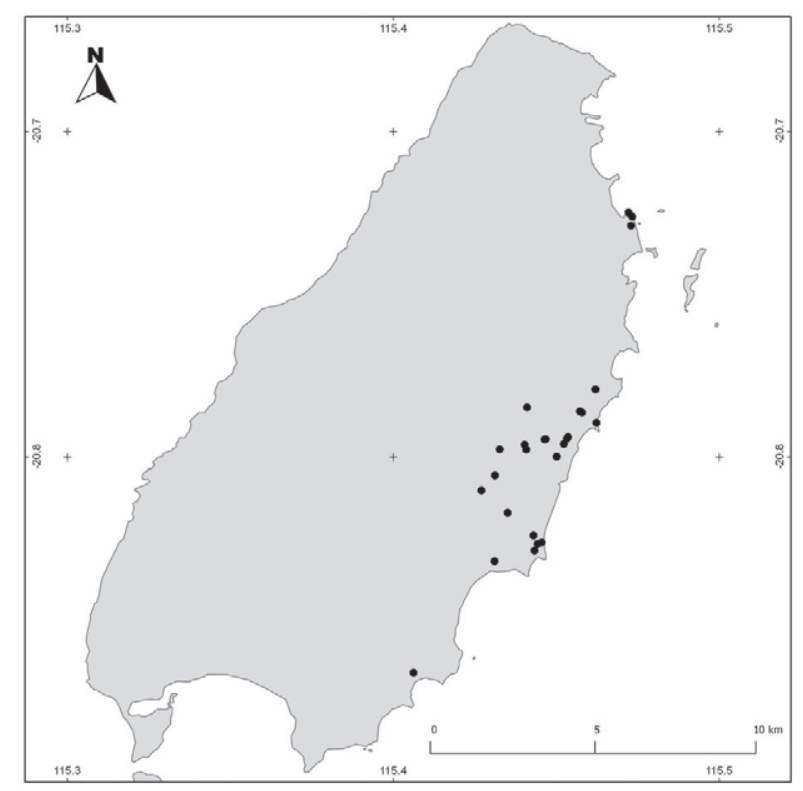

FIGURE 55
Distribution records of Buddelundia sp. 3 on Barrow Island. 


\section{Buddelundia sp. 4}

Figures 33, 35, 36

\section{Buddelundia sp. 5}

Figures 5, 12, 21, 34, 37, 38

\section{MATERIAL EXAMINED}

Australia: Western Australia: Barrow Island:

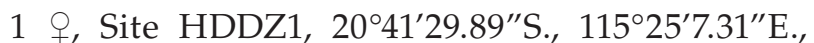
29 September 2011, N. Gunawardene, C. Taylor, window trap (WAM C51765); 1 $\hat{0}, 1$ क, Site HDDZ1, $20^{\circ} 41^{\prime} 35.11^{\prime \prime}$ S., $115^{\circ} 25^{\prime} 12.40^{\prime \prime}$ E., 30 March 2012, N. Gunawardene, C. Taylor, litter sample (WAM C51766); 1 ๙, 1 , Site HDDZ1, $20^{\circ} 41^{\prime} 34.79^{\prime \prime}$ S., $115^{\circ} 25^{\prime} 12.82^{\prime \prime}$ E., 29 September, 2011, N. Gunawardene, night hand collection (WAM C51767); 1 ㅅ․ 1 우, Site GTPZ2, 204'42.39"S., $115^{\circ} 26^{\prime} 52.51^{\prime \prime}$ E., 30 March 2012, N. Gunawardene, C. Taylor, litter sample (WAM C51768); 2 , , Barrow Island Surf Point Beach, $20^{\circ} 41^{\prime}$ S., $115^{\circ} 28^{\prime \prime}$ E., 8 January 2012, K. Edwards (WAM 49699).

\section{REMARKS}

This is an undescribed species known only from four sites on Barrow Island (Figure 56). The principal diagnostic characters are: frontal shield divided into upper and lower sections by a transverse groove; pleonite 3 without interlocking lobes; sulcus arcuatus absent; inner lobe of schisma on posterior corner of first pereonite slightly longer than outer; and large tooth-like lobe on the ventral surface of pereonite 2. The species is pale cream with patches of light brown. This species was not collected in the original baseline study detailed in Callan et al. (2011).

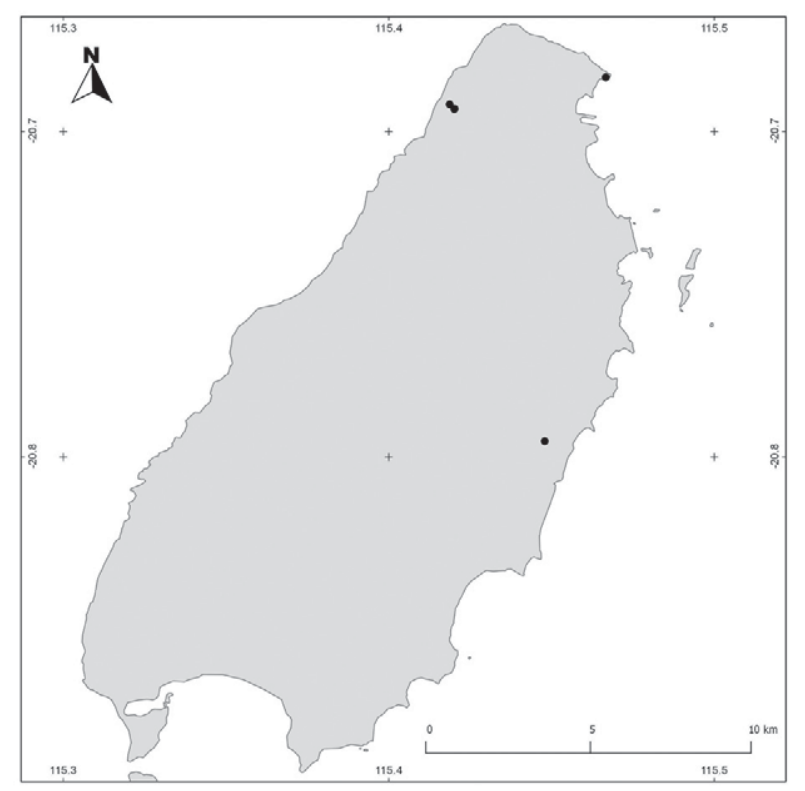

FIGURE 56 Distribution records of Buddelundia sp. 4 on Barrow Island.

\section{MATERIAL EXAMINED}

Australia: Western Australia: Barrow Island:

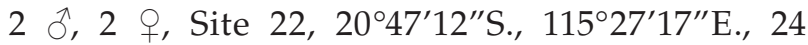
April 2005, S. Callan (WAM C51774); 2 o, 5 ㅇ, Site 45, 20 $47^{\prime} 18^{\prime \prime}$ S., $115^{\circ} 26^{\prime} 31^{\prime \prime}$ E., 24 April 2005, S.

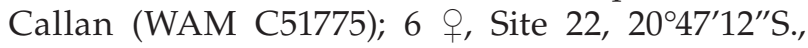
$115^{\circ} 27^{\prime} 17^{\prime \prime}$ E., 17 May 2005, S. Callan (WAM

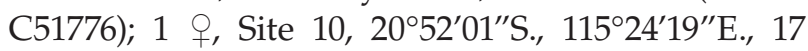
May 2005, S. Callan (WAM C51777); 1 , Site 105, $20^{\circ} 49^{\prime} 07^{\prime \prime}$ S., $115^{\circ} 26^{\prime} 15^{\prime \prime}$ E., 17 May 2005, S. Callan (WAM C51778); 1 ㅇ, Site CC1, 2049'1.33"S., $115^{\circ} 26^{\prime} 14.72^{\prime \prime}$ E., 15 March 2006, S. Callan, R. Graham, pitfall trap (WAM C51779); 1 , Site GP7, 2047'51.40"S., $115^{\circ} 26^{\prime} 26.90^{\prime \prime}$ E., 15 March 2006, S. Callan, R. Graham (WAM C51780); 3 , Site CC2, 2049'2.49"S., 115²6'23.98"E., 15 March 2006, S. Callan, R. Graham, pitfall trap (WAM C51781); 1

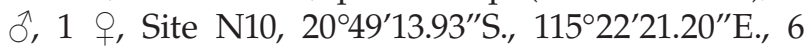
May 2006, S. Callan, R. Graham, pitfall trap (WAM C51782); 3 ㅇ, Site N10, 2049'13.93"'S., $115^{\circ} 22^{\prime} 21.20^{\prime \prime}$ E., 6 May 2006, S. Callan, R. Graham, pitfall trap (WAM C51783); 1 ô, Site N22, 2049'54.98"S., $115^{\circ} 25^{\prime} 13.29^{\prime \prime}$ E., 6 May 2006, S. Callan, R. Graham, pitfall trap (WAM C51784); 2 0, 1 ㅇ, Site N05, $20^{\circ} 51^{\prime} 53.94^{\prime \prime}$ S., $115^{\circ} 24^{\prime} 24.75^{\prime \prime}$ E., 6 May 2006, S. Callan, R. Graham, hand collected (WAM C51785); 1 \%, Site N06, 2047'51.13"S., $115^{\circ} 25^{\prime} 57.60^{\prime \prime}$ E., 6 May 2006, S. Callan, R. Graham, hand collected (WAM C51786); 2 ㅇ, Site N07, 2049'3.91"S., $115^{\circ} 23^{\prime} 6.34^{\prime \prime}$ E., 6 May 2006, S. Callan, R. Graham, winkler sack (WAM C51787); 1 ㅇ, Site N10, 2049'13.93"S., 115 22'21.20”E., 6 May 2006, S. Callan, R. Graham, suction sample

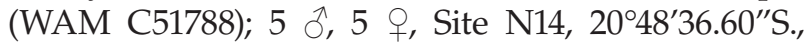
$115^{\circ} 25^{\prime} 37.35^{\prime \prime}$ E., 6 May 2006, S. Callan, R. Graham, hand collected (WAM C51789); 1 \%, Site N17, $20^{\circ} 47^{\prime} 52.63^{\prime \prime}$ S., $115^{\circ} 21^{\prime} 20.41^{\prime \prime}$ E., 6 May 2006, S. Callan, R. Graham, hand collected (WAM C51790); 1 ,

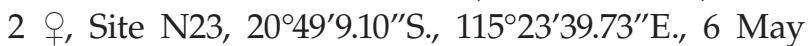
2006, S. Callan, R. Graham, hand collected (WAM

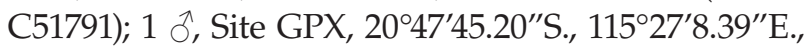
25 September 2006, S. Callan, R. Graham, winkler sack (WAM C51792); 1 ․, Site CC1, 2049'1.33"S., $15^{\circ} 26^{\prime} 14.722^{\prime \prime E}$., 25 September 2006, S. Callan, R. Graham, hand collected (WAM C51793); SJ758,

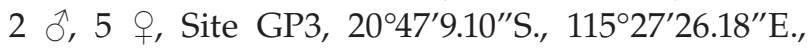
25 September 2006, S. Callan, R. Graham, hand collected (WAM C51794); 1 + , Site GP4, 2047'2.70"S., $115^{\circ} 27^{\prime} 33.54^{\prime \prime}$ E., 25 September 2006, S. Callan, R. Graham, hand collected (WAM C51795); 1

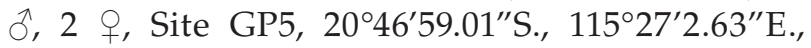
25 September 2006, S. Callan, R. Graham, hand collected (WAM C51796); 1 $\hat{0}, 2$ ㅇ, Site GP6, $20^{\circ} 47^{\prime} 4.71^{\prime \prime}$ S., $115^{\circ} 26^{\prime} 27.75^{\prime \prime}$ E., 25 September 2006, S. 
Callan, R. Graham, hand collected (WAM C51797);

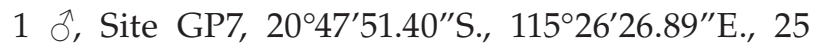
September 2006, S. Callan, R. Graham, pitfall trap (WAM C51798); $30^{\prime}$, Site N05a, 201'58.11"S., $115^{\circ} 24^{\prime} 22.41^{\prime \prime}$ E., 1 May 2007, S. Callan, R. Graham, hand collected (WAM C51799); 3 q, Site N05b, $20^{\circ} 51^{\prime} 50.22^{\prime \prime}$ S., $115^{\circ} 24^{\prime} 23.2^{\prime \prime}$ E., 1 May 2007, S. Callan, R. Graham, pitfall trap (WAM C51800); 2 , Site N07b, 2049'5.63"S., 115²3'8.70”E., 1 May 2007, S. Callan, R. Graham, pitfall trap (WAM C51801);

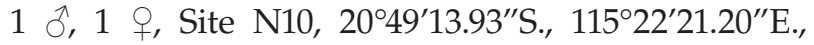
1 May 2007, S. Callan, K. Edwards, pitfall trap (WAM C51802); 3 ô, 1 ㅇ, Site N10, 2049'13.93"S., $115^{\circ} 22^{\prime 2} 21.20^{\prime \prime E}$., 1 May 2007, S. Callan, K. Edwards, hand collected (WAM C51803); 1 क, Site N16, $20^{\circ} 47^{\prime} 47.82^{\prime \prime S}$., $115^{\circ} 21^{\prime} 10.22^{\prime \prime}$ E., 1 May 2007, S. Callan, K. Edwards, pitfall trap (WAM C51804); 10 , Site

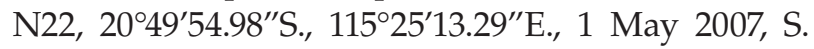
Callan, K. Edwards, hand collected (WAM C51805);

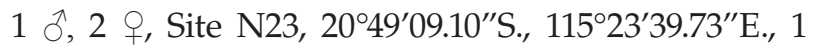
May 2007, S. Callan, K. Edwards, hand collected (WAM C51806); 1 गे, Site AIRZ2, 2051'59.14"S., $115^{\circ} 24^{\prime} 23.69^{\prime \prime}$ E., 30 March 2012, N. Gunawardene, C. Taylor, window trap (WAM C51807); 1 $\hat{0}, 4$ ㅇ,

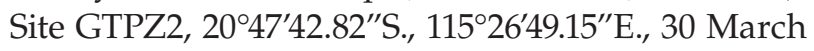
2012, N. Gunawardene, C. Taylor, window trap (WAM C51808); 1 ㅇ, 1 ㅇ, Site GTPZ220 47'42.39"S., $115^{\circ} 26^{\prime} 52.51^{\prime \prime}$ E., 30 March 2012, N. Gunawardene, C. Taylor, litter sample (WAM C51809); 3 $\widehat{0}, 3$ \&, Site N10, 2049'13.93"S., $115^{\circ} 22^{\prime} 21.20^{\prime \prime}$ E., 6 May 2006, S. Callan, R. Graham (WAM C51810).

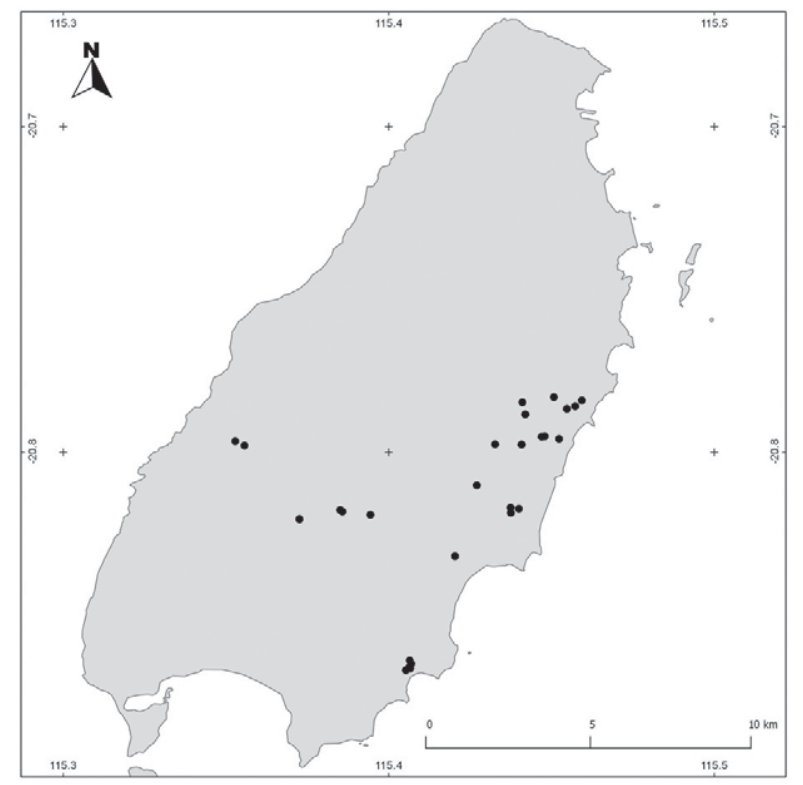

FIGURE 57 Distribution records of Buddelundia sp. 5 on Barrow Island.

\section{REMARKS}

This is an undescribed species characterised by: frontal shield divided into upper and lower sections by a transverse groove; pleonite 3 without interlocking lobes; first pereonite without sulcus arcuatus but with shallow depression; inner lobe of schisma on posterior corner of first pereonite slightly shorter than outer lobe; and moderate tooth-like lobe on ventral surface of pereonite 2 . The species is dark brown with patches of cream. This is the most common isopod collected in the present study and appears widely distributed in the southern half of the island (Figure 57). The species is potentially widespread in the Pilbara (S. Judd unpublished data) but more taxonomic work to assess species boundaries is required.

\section{Armadillidae genus 1}

\section{Armadillidae genus $1 \mathrm{sp} .1$}

Figures $14,15,16$

\section{MATERIAL EXAMINED}

Australia: Western Australia: Barrow Island: 1 옹 Site GP7, 20 $47^{\prime} 51.40^{\prime \prime}$ S., $115^{\circ} 26^{\prime} 26.89^{\prime \prime}$ E., 15 March 2006, S. Callan, R. Graham, pitfall trap (WAM C51811); 1 §, 4 ㅇ, Site WAPZ1, 2043'38.42"S., $115^{\circ} 28^{\prime} 26.63^{\prime \prime}$ E., 29 September 2011, C. Taylor, night hand collection (WAM C51812); 1 ㅇ, Site N22, 2049'54.98”S., $115^{\circ} 25^{\prime} 13.29^{\prime \prime}$ E., 6 May 2006, S. Callan, R. Graham, pitfall trap (WAM C51813); 1

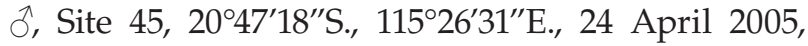
S. Callan, winkler sack (WAM C51814); 1 के, Site N22, $20^{\circ} 49^{\prime} 54.98^{\prime \prime}$ S., $115^{\circ} 25^{\prime} 13.29^{\prime \prime}$ E., 6 May 2006, S. Callan, R. Graham, hand collected (WAM C51815); 1 옹 Site QAPZ1, $20^{\circ} 47^{\prime} 21.75^{\prime \prime}$., $115^{\circ} 27^{\prime} 44.38^{\prime \prime}$ E., 30 March 2012, N. Gunawardene, C. Taylor, night hand collection (WAM C51816); 2 , , Site N14, $20^{\circ} 48^{\prime} 36.60^{\prime \prime}$ S., $115^{\circ} 25^{\prime} 37.35^{\prime \prime}$ E., 6 May 2006, S. Callan, R. Graham (WAM C51817).

\section{REMARKS}

This species represents an undescribed and currently considered monotypic genus known only from five sites on the eastern half of Barrow Island (Figure 58). In contrast to Buddelundia and Barrowdillo it is dorso-ventrally flattened and appears to have limited capacity for conglobation. It is light in colour and the brown pigmentation on the pleon and pereonite 1 is unusual. The genus shares the same arrangement of the pleopod exopodites found in Buddelundia and Barrowdillo; so it is included in the subfamily Buddelundiinae Vandel, 1973. The principal diagnostic characters 


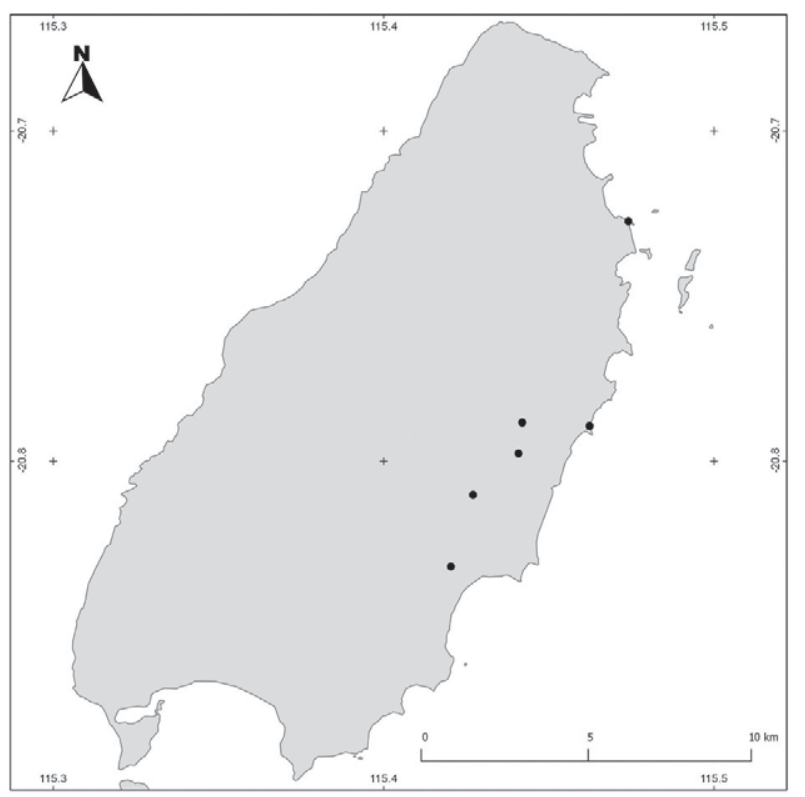

FIGURE 58

Distribution records of Armadillidae genus $1 \mathrm{sp}$. 1 on Barrow Island.

are: pleopod exopodites interlocking, with pleopod 5 covered by pleopod 4; ventral surface of pereonites 1 and 2 without interlocking structures but with small rounded bumps; and uropod exopodites extending almost to the distal margin of the protopodite. This species is only known from Barrow Island and is therefore highly likely a SRE species.

\section{Armadillidae genus 2}

\section{Armadillidae genus 2 sp. 1}

Figure 23

\section{MATERIAL EXAMINED}

Australia: Western Australia: Barrow Island: $1 \delta^{\lambda}$, Site N06a, 2047'34.01"S., 115 25'27.17"E., 1 May 2007, S. Callan, K. Edwards (WAM C51818); 1 juvenile, Site N08, $20^{\circ} 46^{\prime} 44.90^{\prime \prime}$ S., $115^{\circ} 27^{\prime} 43.34^{\prime \prime}$ E., 1 May 2007, S. Callan, K. Edwards, pitfall trap (WAM C51819).

\section{REMARKS}

This species potentially represents an undescribed genus close to Barrowdillo; however, as only one damaged male and a juvenile were collected from two sites during the survey (Figure 59), more material is needed to confirm its taxonomic status. This species had a very similar overall morphology to Barrowdillo except that the epimera are not horizontal in this species.

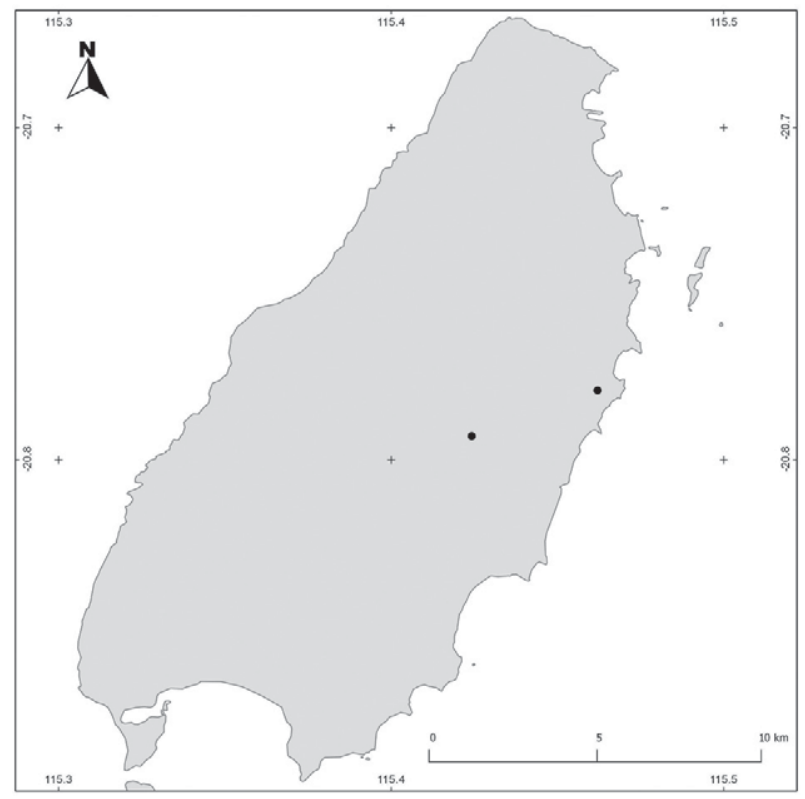

FIGURE 59

Distribution records of Armadillidae genus $2 \mathrm{sp}$. 1 on Barrow Island.

The principal diagnostic characters are: pleopod exopodites interlocking with pleopod 5 covered by pleopod 4; schisma absent on pereonite 1 , but interlocking structures present in the form of a tooth-like inner lobe on ventral surface of epimera 1 and 2; distal part of uropod protopodite longer than broad and tapering; and body with dorsal surface convex and epimera tending horizontal at the margins. This is a potential SRE species.

\section{Armadillidae genus 3}

\section{Armadillidae genus 3 sp. 1}

Figures 13, 39, 42

\section{MATERIAL EXAMINED}

Australia: Western Australia: Barrow Island: $10^{\lambda}$, Site $17,2^{\circ} 47^{\prime} 38^{\prime \prime}$ S., $115^{\circ} 27^{\prime} 24^{\prime \prime}$ E., 17 May 2005,

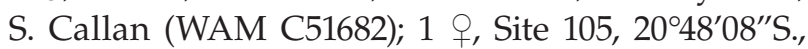
$115^{\circ} 26^{\prime} 48^{\prime \prime}$ E., 17 May 2005, S. Callan, pitfall trap (WAM C51683); 2 , Site GTPZ2, 2047'39.18"S., $115^{\circ} 27^{\prime} 11.77^{\prime \prime}$ E., 30 March 2012, N. Gunawardene, C. Taylor, barrier pitfall trap (WAM C51684); 1 , $20^{\circ} 47^{\prime} 12^{\prime \prime}$ S., $115^{\circ} 27^{\prime} 17^{\prime \prime}$ E., 17 May 2005, S. Callan (WAM C51686).

\section{REMARKS}

This genus differs from the Armadillidae listed above in that the pleopod exopodites are not interlocking and the fifth pair is visible. This is an undescribed species distinguished by: pleopod 
exopodites not interlocking and with the fifth pair visible; uropod protopodite with distal part long and tapering; frontal shield raised form vertex; and dorsal surface with prominent tubercles. It must be noted that the degree of dorsal ornamentation can vary considerably among specimens collected from the same locality. At this stage Armadillidae genus 3 sp. 1 is known from four adjacent sites on Barrow Island and therefore considered an island endemic (Figure 60).

\section{Armadillidae genus 3 sp. 2}

Figure 43

\section{MATERIAL EXAMINED}

Australia: Western Australia: Barrow Island: 1 ㅇ, Site GP6, 2047'4.71'S., 115²6'27.75”E., 15 March 2006, S. Callan, R Graham (WAM C51685).

\section{REMARKS}

This is an undescribed species similar to Armadillidae genus 3 sp. 1, but the dorsal tubercles are absent. This species is represented by a single female found near Armadillidae genus 3 sp.1 (Figure 61). Examination of more material, in particular males, is needed to confirm its taxonomic status. This species is also potentially endemic to the island.

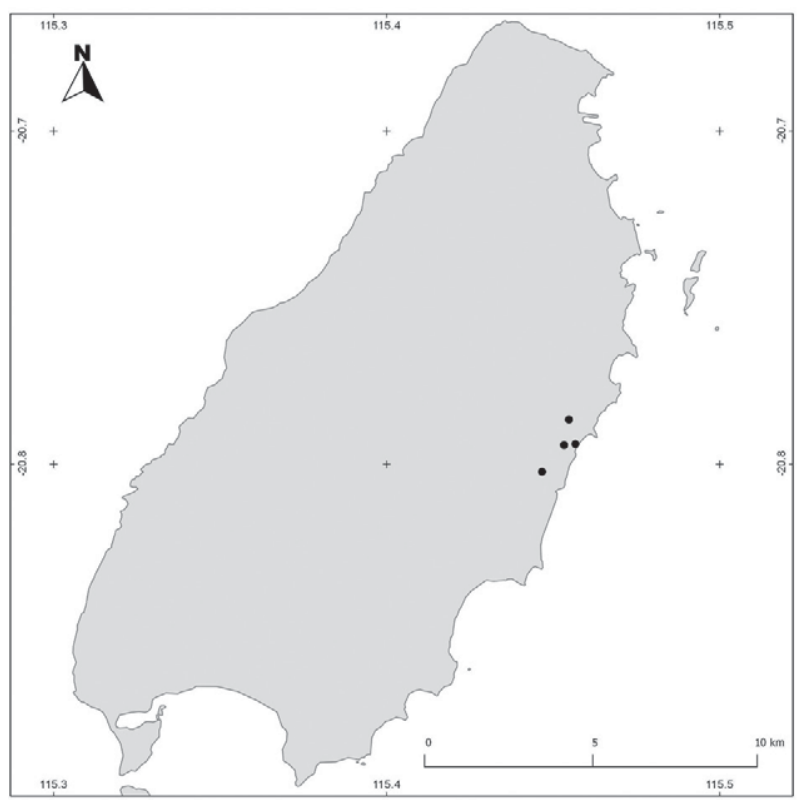

FIGURE 60 genus 3 sp. 1 on Barrow Island.

\section{Armadillidae genus 4}

\section{REMARKS}

This genus shares the same arrangement of pleopod exopodites as Armadillidae genus 3. It differs in that it possess a wide lateral groove on the distal margin of pereonite. 1 Species belonging to this genus are very small (less than $5 \mathrm{~mm}$ ) and rarely collected. Detailed taxonomic studies are needed for a better understanding of their pattern of distribution, but it appears that this genus contains many potential SRE species. Isopods of this genus are widespread in WA (S. Judd unpublished data).

\section{Armadillidae genus 4 sp. 1.}

Figures 40,44

\section{MATERIAL EXAMINED}

Australia: Western Australia: Barrow Island: 1

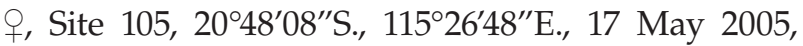
S. Callan (WAM C51687); 2 , Site 10, 2052'01"S., $115^{\circ} 24^{\prime} 19^{\prime \prime}$ E., 17 May 2005, S. Callan, winkler sack (WAM C51688); 5 ふे, 5 क, 5 juveniles, Site CC2, 2049'2.49"S., 115²6'23.98”'E., 15 March 2006, S. Callan, K. Edwards, winkler sack (WAM C51691); 3 , 2 juveniles, Site GTPZ2, 2047'38.50"S., $115^{\circ} 27^{\prime} 15.44^{\prime \prime}$ E., 30 March 2012, N. Gunawardene, C. Taylor, pitfall trap (WAM C51697); 1 , , Site QAPZ2,

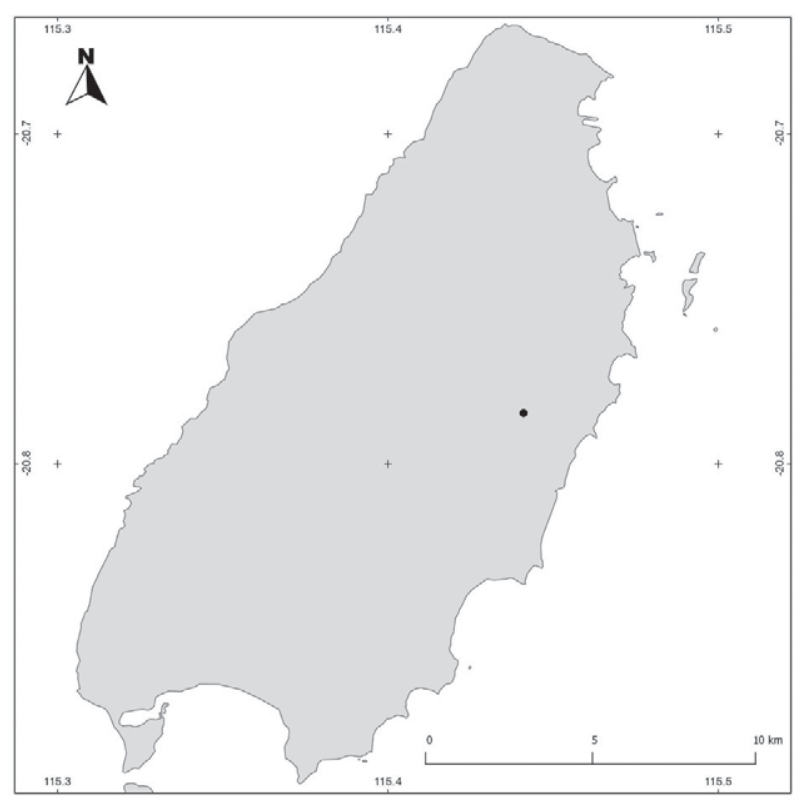
genus 3 sp. 2 on Barrow Island. 


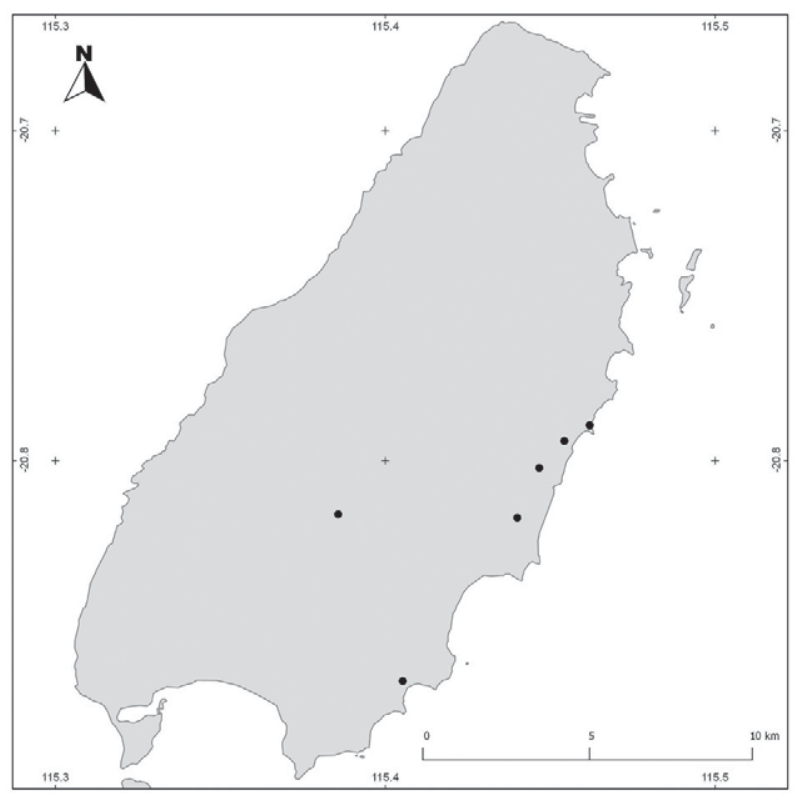

FIGURE 62

Distribution records of Armadillidae genus $4 \mathrm{sp}$. 1 on Barrow Island

$20^{\circ} 47^{\prime} 21.71^{\prime \prime}$ S., $115^{\circ} 27^{\prime} 43.10^{\prime \prime}$ E., 30 March 2012, N. Gunawardene, C. Taylor, barrier pitfall trap (WAM C51698); 1 specimen, Site NO7a, 2048'58.73"S., $115^{\circ} 23^{\prime} 8.57^{\prime \prime}$., 1 May 2007, S. Callan, K. Edwards (WAM C51700).

\section{REMARKS}

This is an undescribed species defined by: pleopod exopodites not interlocking and with the fifth pair visible; distal part of uropod exopodites short and quadrangular; frontal shield flat to vertex; wide lateral groove present on pereonite 1 ; and dorsal surface without conspicuous setae. Its distribution on Barrow Island is shown in Figure 62.

\section{Armadillidae genus 4, sp. 2}

Figures $41,45,46$

\section{MATERIAL EXAMINED}

Australia: Western Australia: Barrow Island:

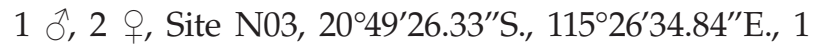
May 2007, S. Callan, K. Edwards, pitfall trap (WAM

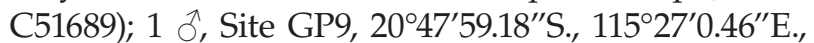
25 September 2006, S. Callan, K. Edwards, pitfall trap (WAM C51690); >50 specimens, Site GPX, $20^{\circ} 47^{\prime} 45.20^{\prime \prime S}$., $115^{\circ} 27^{\prime} 8.39^{\prime \prime}$ E., 15 March 2006, S. Callan, R. Graham, winkler sack (WAM C51692);

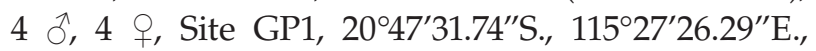
15 March 2006, S. Callan, R. Graham, pitfall trap

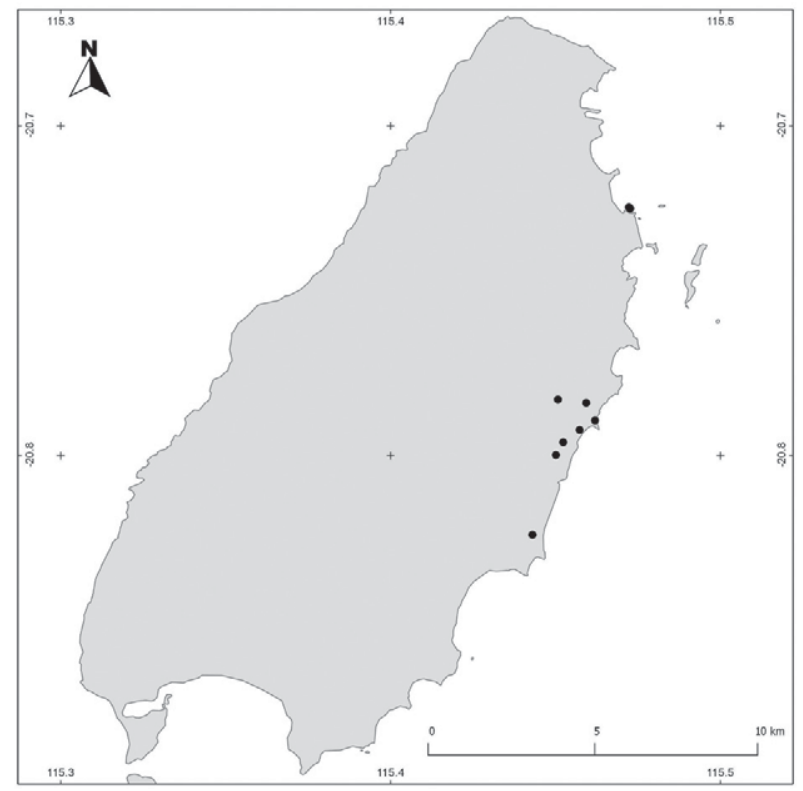

FIGURE 63

Distribution records of Armadillidae genus 4 sp. 2 on Barrow Island.

(WAM C51693); 1 ภ, 1 \&, Site GP4, 2047'2.70"S., $115^{\circ} 27^{\prime} 33.54^{\prime \prime E}$., 15 March 2006, S. Callan, R. Graham, pitfall trap (WAM C51694); $1 \hat{0}, 1$, site GP5, 2046'59.01"S., 115²7'2.63"E., 15 March 2006, S. Callan, R. Graham, pitfall trap (WAM C51695); 1 ô, Site N04a, 2043'28.90"S., 115 28'20.06"E., 1 May 2007, S. Callan, K. Edwards, pitfall trap (WAM C51696);

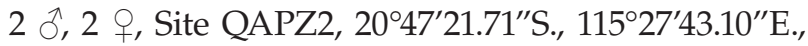
30 March 2012, N. Gunawardene, C. Taylor, barrier pitfall trap (WAM C53622); $1 \hat{0}$, Site WAPZ1, $20^{\circ} 43^{\prime} 30.28^{\prime \prime}$., $115^{\circ} 28^{\prime} 21.67^{\prime \prime}$ E., 30 March 2012, N. Gunawardene, C. Taylor, barrier pitfall trap (WAM C51699).

\section{REMARKS}

This is an undescribed species similar to Armadillidae genus $4 \mathrm{sp}$. 1 but with a narrower lateral groove on pereonite 1 and dorsal surface with conspicuous setae. It is found on the Western half of Barrow Island (Figure 63). More work is needed to establish if the species is found outside Barrow Island but it is likely to be a SRE species.

\section{DISCUSSION}

Four species of terrestrial isopod were known previously from Barrow Island. This study found fourteen additional species, eleven of which are undescribed. The determinations of two nominal species (Ligia exotica and Laevophiloscia yalgoonensis) need to be verified. Three littoral species (Alloniscus 
pallidulus, Ligia exotica, Olibrinus sp.) are present on the island and likely to be more widespread than is indicated here, but they are poorly documented in Western Australia even in the Perth area (Judd and Horwitz, 2003). Only one introduced (non-littoral) species (Porcellionides pruinosus) was present. This is a synanthropic species and was found in close proximity to humans. It has also been collected at one other remote location in the Pilbara and near Leonora (S. Judd unpublished data).

The Armadillidae dominate the terrestrial isopod fauna of much of arid and semi-arid Western Australia. There are likely to be a number of SRE species. For example, the distribution of Barrowdillo pseudopyrgoniscus is limited to Barrow and Varanus Island. Buddelundia hirsuta is potentially also known from the Cape Range but this determination cannot be confirmed without reference to type material because the description is incomplete. Preliminary observations based on unpublished data suggest that most of the species found on Barrow Island found have affinities with the species in the western Pilbara. Taxonomic work/revisions are needed to fully understand species boundaries and distribution patterns. This is particularly needed for the Armadillidae since thirteen of the eighteen taxa recognised here belong to the family.

Two genera (Armadillidae genus 1 and genus 2) share the same pleopodal arrangement as Buddelundia and Barrowdillo which indicates that they belong to the subfamily Buddelundiinae. Both are only known only from either Barrow Island or the western Pilbara. Many species of these genera and Buddelundia have been collected in the Pilbara region since 2005 (S. Judd unpublished data) and many are potential SRE species. Judd and Horwitz (2003) have demonstrated that many species have restricted distribution elsewhere in Western Australia. A systematic study of these taxa with description of the new species and integrated genetic analysis would contribute greatly to a clearer understanding of the biogeography of the isopods in WA and inform the management of areas disturbed by human activities.

\section{ACKNOWLEDGMENTS}

The authors thank Subterranean Ecology, Stirling which made equipment and space available and Nick Dight of Phoenix Environmental Sciences, Balcatta who created the distribution maps. We thank Danny Tang and Volker Framenau for comments on the manuscript and are indebted to Stefano Taiti for providing guidance, taxonomic advice and improvements to the key.

\section{REFERENCES}

Budde-Lund, G. (1912). Oniscoidea, nachglassenes Fragment. In W. Michaelsen and R. Hartmeyer (eds.), Die Fauna Südwest-Australiens Ergebnisse der Hamburger südwest-australischen Forschungsreise 1905. Vol. 4, pp. 17-44. Gustav Fischer: Jena.

Bunn, S.E. and Green, A.J.A. (1982). Oniscoidea (Crustacea: Isopoda) from Rottnest Island, Western Australia. Journal of the Royal Society of Western Australia 65: 147-151.

Callan, S.K., Majer, J.D., Edwards, K. and Moro, D. (2011). Documenting the terrestrial invertebrate fauna of Barrow Island, Western Australia. Australian Journal of Entomology 50: 323-343.

Dalens, H. 1992. Oniscidea (Crustacea, Isopoda) from caves of Cape Range in Western Australia. 1. The genus Buddelundia. Records of the Western Australian Museum 16: 87-102.

Dalens, H. 1993. Two new genera of terrestrial isopods (Crustacea: Isopoda: Oniscidea) from north-western Australia. Records of the Western Australian Museum 16:257-267.

Green, A.J.A., Ferrara, F. and Taiti, S. (1990). Terrestrial isopoda from the Krakatau islands, south Sumatra and west Java. Memoirs of the Museum of Victoria 50: 417-436.

Harvey, M.S. (2002). Short-range endemism among the Australian fauna: some examples from non-marine environments. Invertebrate Systematics 16: 555-570.

Judd, S. and Horwitz, P. (2003). Diversity and biogeography of terrestrial isopods (Crustacea: Oniscidea) from south-western Australia: Organic matter and matter and microhabitat utilisation in seasonally dry landscapes. Crustaceana Monographs 2: 191-215.

Lewis, F. (1998). New genera and species of terrestrial isopods (Crustacea: Oniscidea) from Australia. Journal of Natural History 32: 701-732.

Roux, P. (1828). Crustacés de la Méditerranée et de son littoral, décrits et lithographies par lui- meme. Annales des Sciences Naturelles 16: Paris et Marseille.

Taiti, S. and Humphreys, W. F. (2001). New aquatic Oniscidea (Crustacea: Isopoda) from groundwater calcretes of Western Australia. Records of the Western Australian Museum, Supplement 64: 133-151.

Taiti, S., Paoli, P. and Ferrara, F. (1998). Morphology, biogeography and ecology of the family Armadillidae (Crustacea: Oniscidea). Israel Journal of Ecology 44: 291-301.

Vandel, A. (1973). Les Isopods terrestres de l'Australie étude systématique et biogéographique. Mémoirs du Museum National D'Histoire Naturelle, Nouvelle Série, Série A, Zoologie, Tome LXXXII. Éditions du Muséum: Paris.

Wahrberg, R. 1922. Terrestre Isopoden aus Australien. Results of Dr. E. Mjoberg's Swedish scientific expeditions to Australia, 1910-13. No. 30. Arkiv for Zoologie Stockholm 15:1-298.

MANUSCRIPT RECEIVED 18 MARCH 2013; ACCEPTED 22 AUGUST 2013. 